\title{
Producción local, abastecimiento urbano y regulación municipal: El marco legal del vino de Bilbao (S. XIV-XVI)
}

\section{Local production, urban supply and municipal regulation: The legal frame of the wine in Bilbao (XIV-XVI centuries)}

\author{
Ana María Rivera Medina* \\ UNED (C. A. BIZKAIA)
}

\section{Resumen Abstract}

En el presente trabajo pretendemos analizar la política intervencionista del Ayuntamiento de Bilbao, entre los siglos XIV y XVI, sobre el cultivo, producción y comercialización de vinos, tanto locales como foráneos, en un momento de transición: el paso de la Baja Edad Media al comienzo de la Modernidad. Intentaremos, igualmente, demostrar cómo el Ayuntamiento, máxima expresión

del poder local, regula los distintos ámbitos de la viticultura, con el fin de proteger la producción local frente a la competencia de los vinos foráneos, con el propósito de lograr el abastecimiento de la Villa.

\section{Palabras clave}

Bilbao, viñedos, lagares, vino local, vino foráneo, ordenanzas, abastecimiento, tabernas
The present article analyzes the interventionist politics of the City council of Bilbao, among the XIV and XVI centuries, on the cultivation, production and commercialization of wines, so much local as foreign, in a transition moment: the pass from the Late Middle Ages to the beginning of the Modern period. We will attempt, equally, to demonstrate how the City council, maximum expression of the local power, regulates the different environments of the viticulture, with the purpose of protecting the local production in front of the competition of the foreign wines, with the purpose of achieving the supply of the Villa.

\section{Keywords}

Bilbao, vineyards, wine presses, local wine, foreign wine, ordinances, supply, taverns

* Agradecemos la colaboración de Alfonso Ganuza Arizmendi en documentación, y de Carmen Gómez en diseño gráfico. 
La posición estratégica de la Villa de Bilbao y sus rutas marítimas y terrestres, generó las condiciones para una dinámica economía. Un desarrollo unido a sus vinculaciones marítimas como puerto y puerta de Castilla, pero que no descuidó las necesidades de avituallamiento de la propia Villa. En éste contexto se dio un fuerte impulso a la industria local del vino amenazada por la competencia de los caldos que podían llegar fácilmente desde otras regiones. Por lo tanto, el desarrollo de la vitivinicultura en Bilbao dependía de una compleja red de acciones, que abarcaba tanto las técnicas vitivinícolas como la legislación adecuada, en un medio altamente competitivo. En otras palabras, la historia de los vinos de Bilbao se escribió en forma conjunta entre los viñateros, los bodegueros y la visión estratégica de las autoridades políticas del Ayuntamiento.

En el presente trabajo pretendemos analizar la política intervencionista del Ayuntamiento de Bilbao entre los siglos XIV y XVI sobre el cultivo, producción y comercialización de vinos. La historiografía ha hecho importantes y valiosos estudios sobre la Villa vizcaína, dependiente de una economía marítima. Pesca, navegación, comercio e industria, son temas ampliamente tratados ${ }^{1}$.

Por el contrario, son escasos los estudios específicos sobre la actividad vitivinícola y su regulación dentro del ámbito socio-económico de Bilbao. No obstante, contamos con excelentes publicaciones sobre abastecimiento, mercado y regulación local tanto para Vizcaya ${ }^{2}$, como Álava ${ }^{3}$ y otras zonas peninsulares como Granada 4 , Galicia ${ }^{5}$ o Castilla y León ${ }^{6}$. Pues bien, desde la Baja Edad Media el Concejo (Ayuntamiento-Consistorio) de la Villa impulsó una larga lista de ordenanzas relativas a cultivo, producción, depósito y comercialización de los productos vitícolas.

Es pues nuestro objetivo, dar luz a esta legislación a través de la cual se comprueba una vez más cómo las necesidades de abastecimiento del mercado local

\footnotetext{
${ }^{1}$ Puede Verse al respecto las publicaciones producidas por el Untzi Museoa. Revista Itsas Memoria, $\mathrm{n}^{\mathrm{os}} 1,2,3,4,5$.

2 VVAA: Vizcaya en la Edad Media. San Sebastián, 1985. ARIZAGA BOLOMBURU, B.: «El abastecimiento de las villas vizcaínas medievales: política comercial de las villas respecto a su entorno y a su interior», en La ciudad hispánica durante los siglos XII al XVI. Madrid, 1985, T. I., pp. 293 a 316.RIVERA MEDINA, A. M.: «Pescado, tiempo y distancia. Las conservas de pescado en Vizcaya (S. XV-XVIII)», en Las conservas en el País Vasco. Industria y patrimonio. San Sebastián, 1997. ENRÍQUEZ FERNÁNDEZ, J., SESMERO CUTANDA, E.: Bilbao Medieval. Bilbao, 2000.

${ }^{3}$ BONACHIA HERNANDO, J. A.: «Abastecimiento urbano. Mercado local y control municipal: La provisión de la carne en Burgos», en Espacio Tiempo y Forma. Madrid, 1993, Serie III-5, pp. 85 a 159. PORRES MARUJAN, M. R.: “Alimentación y abastecimiento en Vitoria (S. XVI y XVIII)», en La vida cotidiana en Vitoria en la Edad Moderna y Contemporánea. San Sebastián, 1995, p. 239 a 289. GONZÁLEZ MINUÉS, C.: «Algunos aspectos del abastecimiento de Vitoria en la Edad Media», en Vitoria durante la Edad Media. Actas del Primer Congreso de Estudios Históricos. Vitoria, 1982, pp. 562 a 602.

${ }^{4}$ CASTRO MARTÍNEZ, T. de: El abastecimiento en el Reino de Granada (1482-1510). Granada, 2004. Especialmente el Capítulo X.

${ }_{5}^{5}$ PASTOR, R. y otros: Transacciones sin mercado: instituciones, propiedad y redes sociales en la Galicia Monástica 1200-1300. Madrid, 1999.

${ }^{6}$ HUETZ DE LEMPS, A.: Vinos y viñedos de Castilla y León. Segovia, 2004.
} 
llevan a la institución a reglamentar paso por paso las actividades y los actores en esta producción. Evidentemente el clima, el relieve y la orografía de Bilbao nos permiten aventurar, por una parte, que las heredades dedicadas a este cultivo no serían muchas y; por otra parte, que la calidad de los caldos no sería de excepción. Estas dos limitaciones forzaron la entrada de vinos de otras regiones por mar y por tierra. Caldos que el Consistorio, proteccionista por excelencia, debió regular para mantener su mercado abastecido y no dejar que la actividad local quedara relegada a un segundo lugar.

No obstante, no dejamos de ver, en unas y otras regulaciones, el carácter centralizador del Concejo, la necesidad de controlar el mercado local, y sobre todo los beneficios que en orden a caloñas ${ }^{7}$, visitas ${ }^{8}$, licencias ${ }^{9}$ y arrendamiento $^{10}$, obtenía. No se nos escapa que el fin de esta tendencia intervencionista no era otro que sacar rentabilidad de todas y cada una de las actividades realizadas por los particulares. Sobre todo cuando se trata de una producción escasa y de dudosa calidad, incapaz de competir legal o ilegalmente con vinos franceses, andaluces, canarios, castellanos y riojanos.

A pesar de las limitaciones climáticas y espaciales, como de la condiciones del terreno, la vitivinicultura local podía en determinados momentos del año abastecer a la Villa. Vista la situación de coyunturas de desabastecimiento, y como siempre la realidad se impone, el Consistorio debió legislar y permitir la introducción de vinos foráneos.

Para la elaboración del presente artículo hemos utilizado fuentes publicadas como lo son las «Fuentes Documentales Medievales del País Vasco», colección de incalculable valor para quienes trabajamos la Baja Edad Media y los comienzos de la Modernidad. Asimismo, hemos hecho una profunda consulta de los fondos documentales del Archivo Foral de Bizkaia, especialmente en las secciones Municipal y Judicial.

La documentación de la sección Municipal es de una riqueza incalculable y ha sido muy poco tratada en temas relacionados con la vida urbana y económica de

\footnotetext{
${ }^{7}$ Pena pecuniaria. REAL ACADEMIA ESPAÑOLA: Diccionario de Autoridades de 1726. Madrid, 2002, T. I, p. 76. Significa igualmente calumnia o denuncia. Unos dicen colonia y otros caloña. COVARRUBIAS OROZCO, S. de: Tesoro de la Lengua Castellana o española. Madrid, 1995, p. 237.

${ }^{8}$ Es el acto jurídico, con que algún juez o prelado se informa del proceder de ministros inferiores o súbditos, $u$ del estado de las cosas en los distritos de su jurisdicción pasando personalmente a reconocerlo, o enviando en su nombre a quien lo ejecute. Ibidem, T. III, p. 499. Averiguación, de los jueces o prelados, de cómo viven los visitados, como gastan sus haciendas, como guardan sus estatutos, como administrar justicia. Quien realiza la visita se le conoce como visitador. Ibidem, p. 968.

${ }^{9}$ Es dar autorización. Ibidem, T. II, p. 714. También permiso o beneplácito que se concede para ejecutar alguna cosa. Ibidem, p. 400.

${ }^{10}$ Dar o tomar una renta. Ibidem, p. 122 Tomar o dar en renta alguna hacienda, también el tomar por su cuenta el cobrar rentas reales o públicas, y pagar un tanto cada año por su importe con las calidades que se contienen en la escritura, cuando se hace el arrendamiento. Se llama también al precio o cosa que se toma o alquila., Ibidem, p. 408-409.
} 
Bilbao; por su parte la sección Judicial nos ha proporcionado datos de relevancia en torno a los conflictos generados entre las autoridades y los particulares, como así también permite ir conociendo la mentalidad de este pequeño, pero importante, grupo de actores en torno a la vitivinicultura y el comercio generado a partir del cultivo de la vid.

\section{LA LEGISLACIÓN}

En las villas bajomedievales, el abastecimiento es uno de los temas que más se discutirán en el seno de los Concejos. De ahí que muy pronto aparece un corpus legal que se fundamenta en el proteccionismo de los productos locales frente a la competencia de las mercancías foráneas. Este intervencionismo se da en todos los ámbitos del abastecimiento de villas y ciudades, pero es mucho más acentuado en el caso de los productos alimenticios.

El Ayuntamiento es, por tanto, el organismo que se encarga del control del movimiento de estas mercancías. Legisla sobre cómo se producirán, cómo se almacenarán, cuáles serán las condiciones de venta y quiénes podrán realizar una y otra cosa. Todo con el fin de mantener el mercado abastecido. Villas y ciudades defienden la producción de su alfoz, aunque no siempre lo consiguen. Esta tendencia intervencionista, de protección y control no es nueva. Ya Alfonso X, en Las Partidas, indicaba que antes de fundar una ciudad o villa se debía considerar: la sanidad de los terrenos, el aprovisionamiento de agua y la posibilidad de abastecimiento. Las villas nacen, por tanto, bajo el estigma de una economía dirigida y centralizada.

Y no tardan en tomar medidas apuntando a este objetivo: prohibir o restringir las exportaciones y las importaciones y controlar el mercado ${ }^{11}$. Esta normativa abarca todo tipo de «bastimentos» (abastecimientos), e incluye al vino, producto que no es un alimento como tal, pero que se controla en tanto que aporta una importante cantidad de calorías al cuerpo humano. Sin ser un alimento en sentido estricto, es incorporado a la legislación como tal.

El vino es un producto de consumo masivo y se bebe en grandes cantidades. Para Florencia se ha calculado un consumo, en la baja Edad Media, de 260 litros per cápita, mientras que en otras ciudades como Bolonia el consumo se triplica, y en Arlés se llega a los 230 litros per cápita/año. Es decir, que se puede suponer que dependiendo de las condiciones de abasto, se bebían por habitante y año, entre 150 y 250 litros.

Este promedio puede reducirse en lugares donde el vino competía con otros productos locales como sidra, cerveza o hidromiel. La sidra gana terreno a partir

${ }^{11}$ CARLÉ, M. del C.: «Notas para el estudio de la alimentación y abastecimiento en la Baja Edad Media», en Cuadernos de Historia de España. Buenos Aires, 1977, p. 289. 
del siglo XII y experimenta gran difusión en el País Vasco y Galicia ${ }^{12}$. La Villa de Bilbao no sería un excepción; aunque no se conocen cifras sobre el consumo percápita, las fuentes indican porque los caseros en la mayor parte del tiempo estavan en las dichas tavernas. ${ }^{13}$.

Siendo pues el vino un producto de primera necesidad, en tanto que era susceptible de una gran demanda, no tardaron en surgir en la Villa disposiciones referentes a su producción, venta y consumo. En 1372 Juan I confirma el Fuero de Bilbao y remarca la libertad de los bilbaínos a labrar tierras y huertas en su distrito ${ }^{14}$. Ya en el Fuero de Vizcaya se introducen medidas respecto a las viñas, pero también a los manzanales. Es decir, en las tierras de la Villa se producía vino y sidra muy tempranamente. Pero también en épocas tempranas se protegían los cultivos contra furtivos, contra los excesos y contra las malas artes imponiendo fuertes caloñas a los transgresores ${ }^{15}$.

Poco más tarde, en 1399, cuando Enrique III ratifica las Ordenanzas Municipales de Bilbao, se remarca la importancia que tiene el vino para la vida de la Villa. Así pues, se establecen: la prohibición de introducir vinos de otras ciudades, la autorización ante la falta del producto para adquirirlo en otros mercados por el bien de la Villa, las imposiciones fiscales a caldos foráneos y la libertad impositiva para los propios, así como que para consumo personal sólo se podía introducir una cánta$\mathrm{ra}^{16}$. Y así un suma y sigue de medidas proteccionistas, de control y vigilancia del consumo.

\section{EL PAISAJE VITÍCOLA}

La ciudad y la villa medieval eran el pulmón económico, la unión entre el campo productor de materias primas y el centro urbano demandante de las mismas. A veces uno y otro se confundían, no se sabía con claridad donde terminaba lo urbano y comenzaba lo rural. Esto es lo que sucede en Bilbao: pequeños viñedos muy cercanos al casco de la Villa, casas con huertas y viñas constituían un paisaje poco común junto a la ría.

12 FLANDRIN, J., MONTANARI, M.: Historia de la Alimentación. Madrid, 2004, p. 553/554.

${ }^{13}$ Diputación Foral de Bizkaia - Archivo Foral (en adelante DFB - AF): Archivo Municipal de Bilbao (en adelante AMB), Sección Antigua (en Adelante SA) 004/003/005. Bilbao, 13 de Noviembre de 1554, insertas en este documento: Ejecutorias referidas a 1505 y 1506.

${ }^{14}$ Colección documental del Archivo Histórico de Bilbao (1300-1473), en Fuentes documentales medievales del País Vasco». Bilbao, 1999, n 90, p. 71 a 77.

${ }^{15}$ Fuentes Jurídicas medievales del Señorío de Vizcaya, en Fuentes documentales medievales del País Vasco. San Sebastián, 1986, n 8, p. 8 y 144, Fuero Nuevo, Título 34, ley 15.

${ }^{16}$ Privilegio Enrique III. Valladolid, 20 de setiembre de 1399. Colección documental..., Op. Cit., Doc. 47. También puede verse Colección documental del Archivo General de Vizcaya, en Fuentes documentales medievales del País Vasco. San Sebastián, 1986, n 9, Doc. 5. Madrid, 15 de diciembre de 1393. 
Lo primero que legislan los ayuntamientos son medidas que protegen a la producción local, sin importar la calidad, sino la cantidad de la misma. Proteger las producciones locales era sinónimo de vetar la introducción de productos similares de otras zonas y regiones. De hecho, en la Villa se tenía mucho cuidado en introducir vinos de las anteiglesias vecinas ${ }^{17}$. En Bilbao la competencia no sólo proviene de las regiones colindantes, sino también de las arribadas efectivas o maliciosas por mar. Siendo la economía bilbaína una economía marítima y con relaciones en los principales puertos europeos, no es de extrañar el celo del Consistorio a este respecto.

Las heredades dedicadas al cultivo de viñas, manzanales y huertas estaban protegidas por la legislación vigente. El Concejo regulaba la situación, linderos o tapiales divisorios, controlaba el cuidado de los cultivos y era extremadamente celoso a la hora de tratar las denuncias de los vecinos, con motivo de algún altercado en las viñas. El Fuero Nuevo establecía duras penas para aquellos que hurtasen en manzanales o viñedos, condenando a muerte al ladrón ${ }^{18}$. La intromisión de animales en las heredades era otro aspecto a tener en cuenta, condenando al dueño de los animales a pagar por cada puerco un maravedí, por cada oveja o cabra, tres maravedíes, además de subsanar el daño que hubiese ocasionado en la viña ${ }^{19}$.

Muy duras eran también las penas impuestas a aquellos que arrancasen cepas, ya que los condenaban a muerte, o a dos años de destierro ${ }^{20}$, inscritas éstas en el Fuero Viejo. Este punto fue largamente tratado en las Ordenanzas de la Villa desde comienzos del siglo XV. En 1489 se prohibía entrar a las heredades a hacer daño, sacar sarmientos, cepas, maderas, palizadas ${ }^{21}$, so pena de 50 azotes $^{22}$. Al parecer, las heredades no estaban muy bien protegidas, de tal manera que las bestias y los animales menores entraban con frecuencia produciendo grandes destrozos ${ }^{23}$. Las averías producidas llegaron a ser tales que un año más tarde se ordena que nadie pueda entrar en las viñas sin licencia de su dueño ${ }^{24}$.

Los destrozos en los viñedos no eran un problema nuevo, ya que para comienzos del siglo XV aparece la figura del costijero ${ }^{25}$, individuo encargado de vigi-

17 Ordenanzas Municipales de Bilbao (1477-1520), en Fuentes documentales medievales del País Vasco. Bilbao, 1996, $n^{\circ} 70$, p. 37. Bilbao, 5 de mayo de 1480

${ }^{18}$ Fuentes Jurídicas..., Op. Cit., p. 101

19 Ibidem, p. 144.

${ }^{20}$ Diputación Foral de Vizcaya: El fuero, privilegios, franquezas y libertades del M. N. y M. L. Señorío de Vizcaya. Bilbao, 1977, p. IX, Título 34: De las penas y daños.

${ }^{21}$ Del occitano palizada. Empalizada. Terreno cercado con estacas. MOLINER, M.: Diccionario del uso del español. Madrid, 2002, p. 546.

22 Ordenanzas Municipales..., Op. Cit., p. 65/66. Bilbao, 16 de enero de 1489.

${ }^{23} \mathrm{Ibidem}$, p. 25. Bilbao, 24 de febrero de 1478.

${ }_{24}$ Ibidem, p. 27. Bilbao, 19 de marzo de 1479. p. 74, Bilbao, 11 de julio de 1491. p. 79, Bilbao, 9 de febrero de 1495

${ }^{25}$ Puede verse Libros de Autos Judiciales de la Alcaldía (1419-1499) y Libro de Acuerdos y Decretos Municipales de la Villa de Bilbao, en Fuentes documentales medievales del País Vasco. San Sebastián, $1995, n^{\circ} 55$. 
lar las heredades en las que había plantaciones. Probablemente los desmanes continuaban porque en 1509 y 1515 se asigna un elevado salario a los costijeros, 600 maravedíes, que pagarían los mismos propietarios, pero estaría sujeto a la autoridad del Concejo ${ }^{26}$. Los costijeros cuidaban con mayor celo las viñas en los periodos previos a la vendimia ${ }^{27}$, desde la parte de la Puente hasta Abando.

Había otros costijeros, tal es el caso del que custodiaba las heredades allende del río. A éste le dieron además autorización para detener a quien robase madera o fruta ${ }^{28}$. Cuestión nada banal, porque los viñedos se levantaban en forma de parral ${ }^{29}$ y éstos se sustentaban con madera ${ }^{30}$. La madera servía para sostener el tronco y mantener la viña en pie a manera de tutor; y por supuesto si no hay frutos, no hay cosechas. Madera y vid debían cuidarse porque todo redundaría, posteriormente, en la calidad de los caldos.

No obstante, algunos vecinos pedían licencia al Concejo para de su propio pecunio pagar un cuidador de sus cultivos. En 1515 Juan Martínez, de Bilbao La Vieja manifiesta ante las autoridades que tenía en la campa de Begoña y Sendeja una viña y manzanal, y que por su propiedad pasaban los viandantes que se dirigían a la taberna de Arecheta en la Sendeja, provocando verdaderos destrozos ${ }^{31}$. Tal como se observa no todos los destrozos llegaban a la categoría de delito, sino simplemente de descuido y cierta cuota de picardía.

Los extraños y las bestias no eran los únicos causantes del destrozo de las viñas. Algunos agentes meteorológicos producían graves daños. La piedra, los pedriscos, los turbones y relámpagos hacían también muchos daños. En ocasiones se recurría a la Iglesia, porque hera aquello serbiçio de Dios e bien de la república de la dicha Villa ${ }^{32}$, para que bendijera los cultivos y protegiera de estos fenómenos.

Pero el Consistorio no pudo dejar a Dios una causa tan importante. Y dado que no podía prevenir estos accidentes, intentó poner solución una vez acaecidos los mismos. Sobre todo en los llamados turbones. El turbón ${ }^{33}$ es un golpe de agua muy recio que lleva consigo tierra y arena, de ahí que el líquido elemento sea turbio, denominándose este fenómeno turbón. Al parecer este fenómeno era frecuente por-

${ }^{26}$ Libros de Acuerdos y Decretos Municipales de la Villa de Bilbao (1509-1515), en Fuentes Documentales medievales del País Vasco. Bilbao, 1995, n 56, p. 106 Bilbao, 1509. p. 275. Bilbao, 1515.

${ }_{27}$ Ibidem, p. 275. Costijero para Abando. Bilbao, 7 de agosto de 1515.

${ }^{28}$ Ibidem, p. 138. Valladolid, 18 de setiembre de 1509.

${ }^{29}$ Para el norte de España una de las primeras referencias a parrales se encuentran en 1171 en Nájera. Este sistema se solía utilizar sobre la glera en las orillas de los ríos. BARRIO, F. A.: «Algunas noticias contenidas en la documentación medieval riojana publicadas hasta la fecha, sobre los tipos de vinos y sus métodos y técnicas de elaboración, en la Rioja, en la Edad Media», en Actas del I Encuentro de Historiadores de la Vitivinicultura española. Puerto de Santa María, 2000, p. 86.

${ }^{30}$ Recibe el nombre de rodrigón. Esta denominación pasa, más tarde a los viñedos americanos.

${ }^{31}$ Ibidem, p. 246. Bilbao, 15 de junio de 1515.

32 Ibidem, p. 227. Bilbao, 4 de mayo de 1515.

${ }^{33}$ COROMINAS, J.: Diccionario etimológico de la lengua española. Madrid, 1990, p. 942. 
que el Concejo de la Villa nombra a una persona encargada de echar e quitar los turbones ${ }^{34}$.

Los viticultores, conocedores del clima de la Villa, optaron por el sistema de emparrado o parral y no por el de viña de arrastre o de baja altura, más propia de las regiones de secano. El parral, en este caso, proporciona el aislamiento necesario entre la canopia ${ }^{35}$ y la base del tronco; además aquélla tenía así una mayor exposición al sol, dado que el emparrado permite la extensión de las ramas, un mayor desarrollo de los pámpanos, y menor contacto con la humedad del suelo ${ }^{36}$.
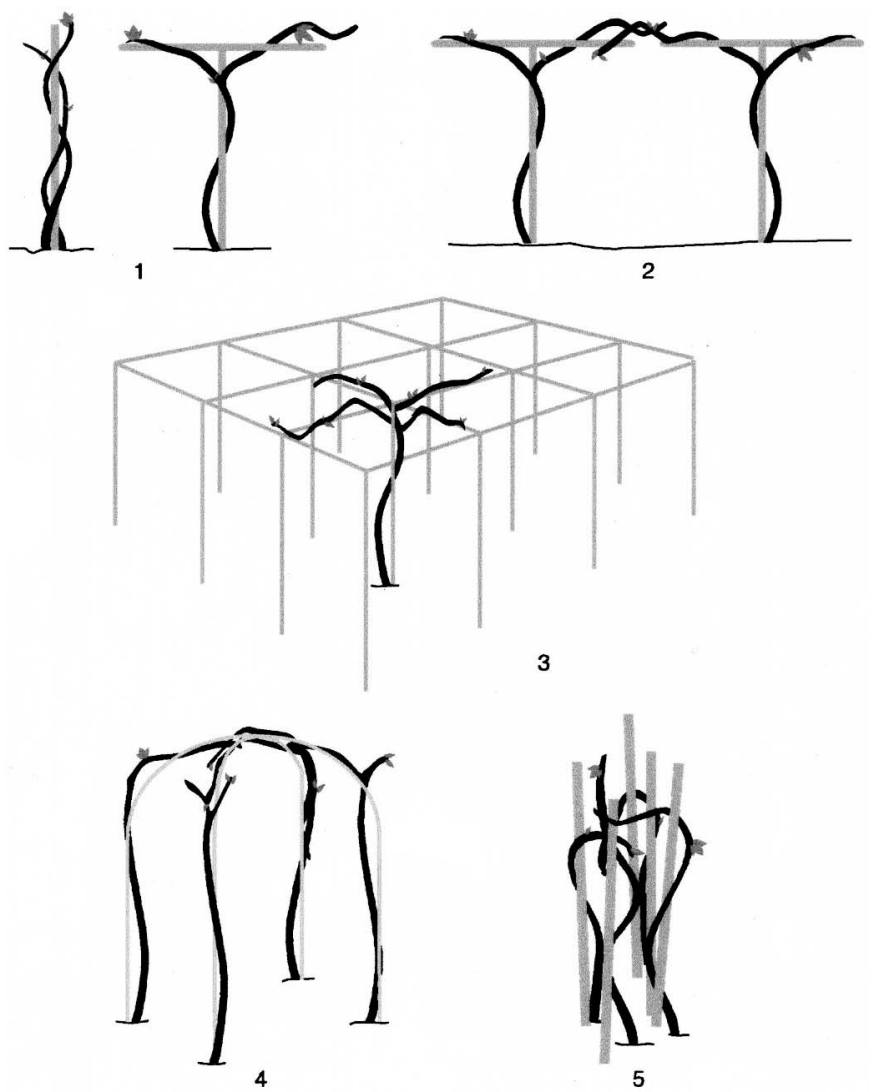

Disposición de las viñas en emparrado: tipos

\footnotetext{
${ }^{34}$ Libros de Acuerdos y Decretos Municipales de la Villa de Bilbao, Op. Cit., p. 276. Bilbao, 29 de agosto de 1515

${ }^{35}$ Del inglés canopy, significa follaje. MARTíNEZ, M.: El vino de la $A$ a la $Z$. Santiago de Chile, 2005 , p. 61.

${ }^{36}$ UNWIN, T.: El vino y la viña. Barcelona, 2001.
} 
Las viñas, los manzanales y las casas se emplazaban sin solución de continuidad dentro de los límites de la Villa, y a veces fuera de ella: Uribarri ${ }^{37}$, Zaballa ${ }^{38}$, Begoña ${ }^{39}$, allende la puente son buenos ejemplos ${ }^{40}$. Las que estaban situadas dentro de la Villa debían regirse por las Ordenanzas Municipales y pedir autorización para cualquier modificación que el propietario quisiera realizar. Estas peticiones tenían que ver, la mayoría de las veces, con modificaciones en tapiales, la edificación de lagares y bodegas de almacenaje. En estos casos el Ayuntamiento solía pedir planos de obras y también enviaba peritos al lugar ${ }^{41}$. Y las que estaban emplazadas fuera de la jurisdicción de la Villa eran constantemente vigiladas, sobre todo tras la vendimia, porque no tenían la misma consideración jurídica que las anteriores. Y se trataba de evitar que se introdujeran vinos de aquellas heredades que, a los efectos, eran considerados como foráneos.

En su afán intervencionista el Concejo obligaba a todos aquellos que plantasen viñas a registrarlas en el padrón municipal, imponiendo fuertes multas a todos los que lo hicieren sin autorización. De ahí que aparece la figura del veedor, persona que se encargaba de controlar la evolución de las heredades. Una vez comprobada la existencia de un majuelo ${ }^{42}$ sin empadronar, se obligaba a su dueño a hacerlo en el menor tiempo posible ${ }^{43}$. Además, si una viña no estaba empadronada, no podía vender los vinos producidos tras la vendimia, y se imponía al transgresor una pena de 5000 maravedíes (en adelante mrs.), amén de quemar sus cubas en la plaza ${ }^{44}$. Pero también vigilaba el origen de los cultivos, prohibiendo terminantemente que se hiciesen viñas de sarmientos ${ }^{45}$. Esta tendencia dirigista puede llegar a entenderse si se tiene en cuenta que de la producción local dependía el abastecimiento de la Villa. Y a mayor producción local, menor era la necesidad de recurrir a productos foráneos.

El Concejo era, igualmente, cuidadoso a la hora de controlar que no se hicieran cultivos, ni edificios destinados a vinos y sidra, fuera de los términos de la Villa, es-

${ }^{37}$ Libro de Autos..., Op. Cit., p. 23. Bilbao, 18 de setiembre de 1440. Bilbao, 14 de agosto de 1444. Bilbao, 243 de abril de 1430.

38 Ibidem: p. 61. Bilbao, 15 de marzo de 1437.

39 Ibidem, p. 147. Bilbao, 4 de julio de 1499.

40 Ibidem, p. 164. Bilbao 7 de marzo de 1501.

41 Ibidem: Bilbao, 18 de abril de 1509. Pero de Yennegues (léase Iñiguez) de Henderica que tenía casa y viña cuya tapia estaba pegada al camino. El Ayuntamiento envió un perito y determinó que el propietario del tapial debía dejar una servidumbre entre dicho tapial y el camino, p. 67. Bilbao, 27 de junio de 1509. Juan de Arbolancha de la Torre pide licencia para edificar en el camino de Abando casa para lagares y vivienda, donde tenía previamente la casa vieja. El Concejo manda, antes de resolver el asunto, al carpintero para que observe la calidad y condiciones de la construcción que se pretende hacer, p. 100. Bilbao, 12 de setiembre de 1509. Juan Sáez de Lascano había hecho una pared en Zaballa. Dicha pared dividía sus viñas de la calzada municipal. No obstante, de no haber pedido autorización, el Consistorio tras enviar a los peritos la autoriza, p. 131.

42 Viña entre uno y tres años. Recuérdese que una viña produce tras cinco años de ser plantada.

${ }^{43}$ Libro de Acuerdos..., Op. Cit., p. 148. Bilbao, 31 de octubre de 1509. Se le ordena a Martín Sáez de Anuncibay empadronar el majuelo de su propiedad.

${ }^{44}$ Ordenanzas, Op. Cit. p. 98. Bilbao, 26 de febrero de 1492.

45 Ibidem, p. 228. Bilbao, 4 de enero de 1510. 
pecialmente en los llamados «revales (arrabales). Para mantener el control sobre las edificaciones y sobre los ingresos tanto por las construcciones, como por las producciones o sus ventas, prohíbe terminantemente construir, so pena de 1000 mrs., la mitad destinado a los reparos de la villa, y la otra mitad para la justicia ${ }^{46}$. No obstante la ordenanza fue letra muerta. Los arrabales y entorno de la Villa se llenaron de viñedos y huertas.

El Consistorio no dejaba al azar ningún aspecto de las actividades productivas. Tan es así que cada año pregonaba el día en que debía iniciarse la cosecha, dejando por sentado que era un trabajo que sólo competía a los vecinos: que en este presente agosto é cosecha que se a de facer de los vinos de las viñas de esta Villa de Bilbao é de su derredor é comarca, impidiendo que se envasen vinos de fuera del distrito ${ }^{47}$.

Aunque el tiempo normal de cosecha en la península suele ser el mes de septiembre, en Bilbao esta actividad se adelantaba. El Ayuntamiento esperaba que la vid tuviese un cierto grado de madurez y fijaba la fecha de la cosecha anticipadamente, dado que el mes de septiembre, generalmente, es muy lluvioso y la humedad y el agua pudrirían las $u_{v a s}{ }^{48}$. Es decir, adelantando la cosecha se asegura el abastecimiento de vinos del lugar.

Las autoridades realizaban, asimismo, un seguimiento del estado de los lagares y de las mejoras que hacían sus dueños, para las cuales también debían pedir licencia. Cualquier cambio o mejora de las instalaciones debía ser informado al Ayuntamiento. De estas peticiones deducimos que en Bilbao se utilizaba el típico lagar romano, porque las licencias se suelen pedir para el mantenimiento o para cambiar la madera, que generalmente era de haya ${ }^{49}$.

Los lagares los utilizaban para la elaboración de sidra y de vino, pero al parecer no todos los viñedos y manzanales tenían su propio lagar, porque en auto del siglo XV se indica que no tenían los vecinos de la dicha Villa tantos lagares como debyan tener para majar mançana ${ }^{50}$ y pisas (uva) e apurar la raspa del agosto de

\footnotetext{
${ }^{46}$ Ibidem: p. 21/22.

${ }^{47}$ DFB - AF, AMB, SA: 0305/001/007. Bilbao, 23 de agosto de 1535. Pleito que se sigue contra San Juan de Bermeo por la introducción de chacolí.

${ }^{48}$ Se genera un hongo Botrytis. Este hongo puede producir Podredumbre noble o podredumbre mala. En el caso del clima de Bilbao generaba la segunda. Esto también nos puede permitir comprender cuando se define a los viñedos de la Villa como pestíferos. También las plantas bilbaínas podían ser atacadas por otro hongo el oidio, que ataca las partes verdes de las platas, dejando un aspecto polvoriento. Las hojas se caen disminuyendo la calidad y volumen de la cosecha. Sus esporas se reproducen más rápidamente en condiciones de calor y humedad. Puede verse: Martínez, Mariana: El vino..., Op. Cit., p. 51.

${ }^{49}$ Libro de Acuerdos..., Op. Cit., p. 258/259. Bilbao, 6 de julio de 1515.

${ }^{50}$ Kepa Sagastizal y Miguel González consideran que el viñedo en Vizcaya y Guipúzcoa se expande a costa del manzanal, resulta escaso en el ámbito rural y es visible en el urbano. Sagastizabal, Kepa, González, Miguel: «Historia de la vitivinicultura en el País Vasco Atlántico», en Actas del I Congreso Internacional de la Historia de la Vid y el Vino. Vitoria, 1996, p. 242.
} 
las dichas vynnas e mançanales ${ }^{51}$. No obstante, existieron lagares en Iturriaga ${ }^{52}$, Ibaizábal ${ }^{53}$, Uribarri ${ }^{54}$ y allende la puente ${ }^{55}$.

De hecho, los lagares no despertaron gran interés por parte de los regidores, porque no existían normativas respecto de las instalaciones, uso, mantenimiento, como tampoco hemos encontrado ninguna tasa impuesta a la elaboración de los caldos. Llama asimismo la atención que la legislación no hiciera referencia, tampoco, a ordenanzas sobre la elaboración por parte de terceros, ni a las circunstancias en las que ésta se debía realizar. La maquila era una realidad de hecho, pero no de derecho, según la jurisprudencia consultada.

\section{EL VINO DE LOS VECINOS}

La regulación sobre el uso, venta y consumo de los vinos locales queda ampliamente estipulada en las Ordenanzas de la Villa de Bilbao, ratificadas por Privilegio otorgado por el Rey Don Enrique III en 139956. Dichas Ordenanzas son las que más referencias hacen al trasiego del vino local. Pero antes de analizarlas se debe establecer qué se entiende por vinos de la Villa y, para ello, hay que referirse a los términos de la misma. En la Carta Puebla se establecen los límites de la Villa:

«... Et otorgo vos que ayades por terminos desde como toma el puntal de fondon de çorroça do se yuntan amas las aguas ribera del agua arriba que viene de ualmaseda ffasta el arroyo que uiene por ssomo del campo de çornoça que en derecho de percheta. Et dende do pega el arroyo dacordoyaga. Et dende assi como va el cerro a arriba ffasta el sel de eguiluz et a ffagasarri et a olaluçeta et a buyana de susso, asi como viene por çima de la ssierra. Et al uado de echauarri. Et dende de como ua el camino de echauarri ffasta çima la ssierra de ganguren, et dende ffastal puntal de fondon de deustu en derecho de luchana, asi como auedes parados los terminos e amojonados con tales los de çamudio et de alffoz duriue. Con todas las anchuras et egidos et montes et aguas et logares que en los dichos terminos ha., $\$ 7$

La Carta Puebla y, más tarde, las ordenanzas de la Villa facultaban a sus vecinos a labrar viñas y, tácitamente, a elaborar vinos. Los monarcas y las autoridades bilbaínas estimularon las producciones locales debido a las grandes dificultades de abastecimiento, causadas tanto por las distancias, como por la falta de tecnología para mantener ciertas mercancías en buen estado. De ahí que una de

\footnotetext{
${ }^{51}$ Libro de Autos, Op. Cit., p. 164. Bilbao, 7 de marzo de 1501.

52 Ibidem, p. 70. Bilbao, 8 de julio de 1431.

${ }^{53} \mathrm{Ibidem}$, p. 94 a 94. Bilbao, 23 de agosto de 1445.

${ }^{54}$ Ibidem, p. 171. Bilbao, 16 de enero de 1458.

${ }_{55}$ Ibidem, p. 129. Bilbao, 25 de agosto de 1495. p. 164. Bilbao, 7 de agosto de 1500.

${ }^{56}$ DFB - AF, AMB, SA: 0199/001/026.

${ }^{57}$ Carta Puebla de Bilbao año de 1300, en Revista Oficial del 700 Aniversario de la Fundación de Bilbao. Bilbao, 2000.
} 


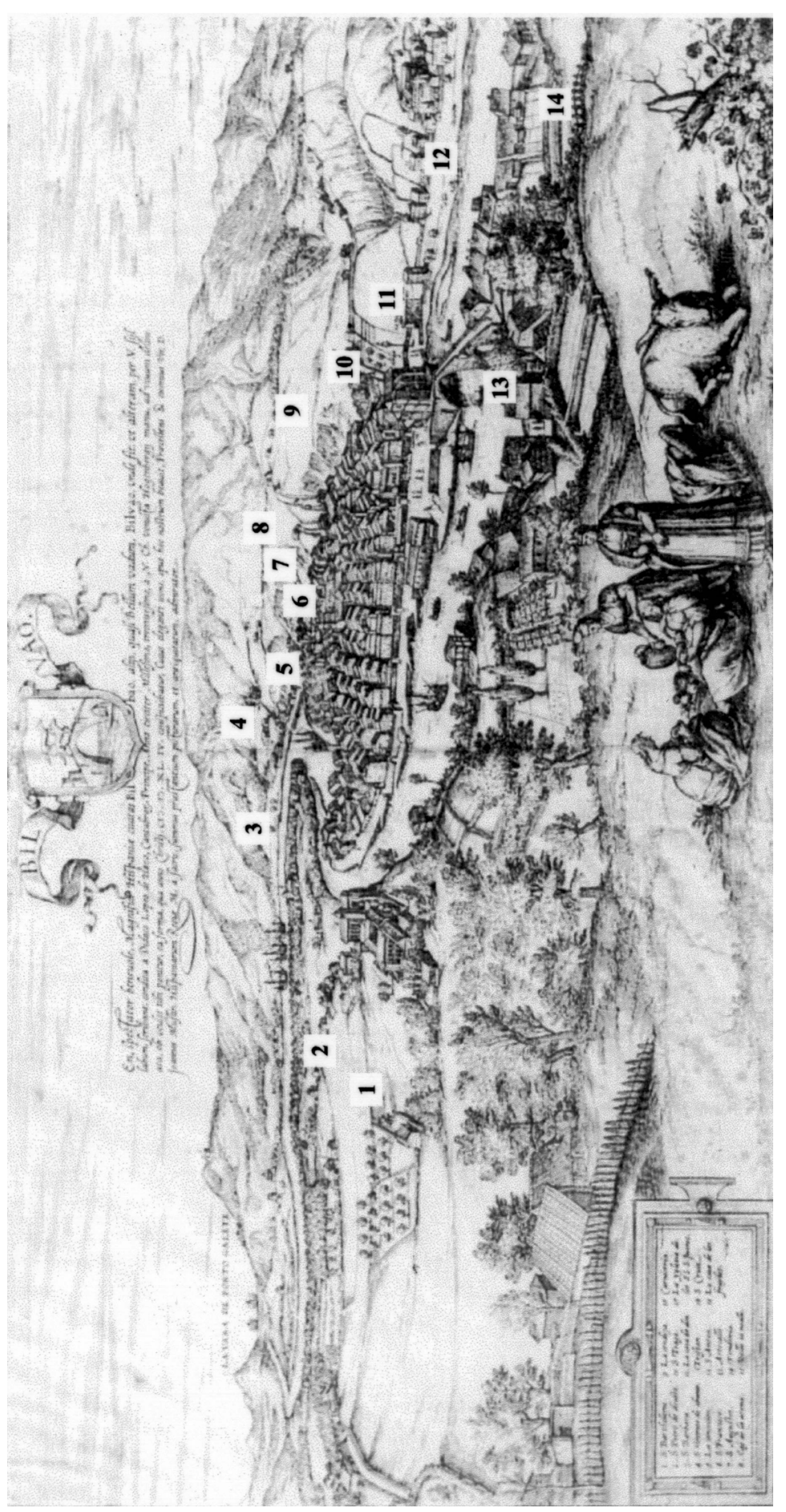

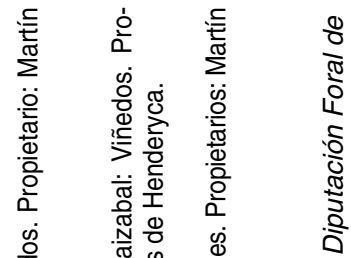

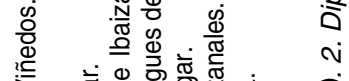

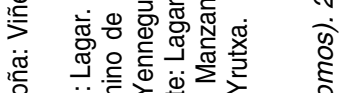

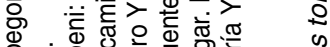

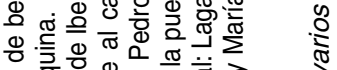

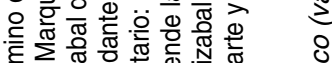

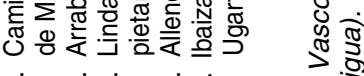

文

을

ஸ் ฏ

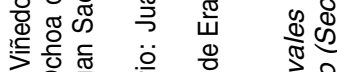

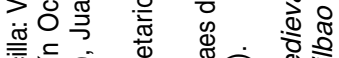

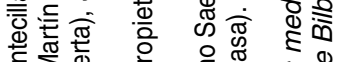

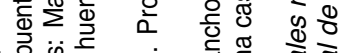

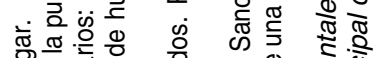





ช



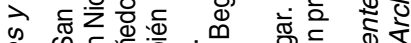

๙

ช

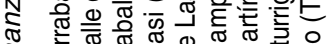

.

कांत

冚

은 $\dot{0}$ 응

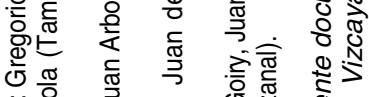

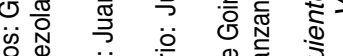

은 坖

응용 흥

은 은 은 ㅇํㄴ

ம்

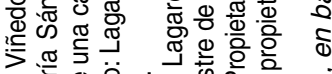

๙்

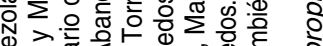

है

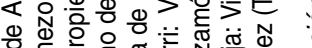

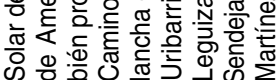

त $\dot{\square}$ 
las primeras ordenanzas haya sido que los vinos elaborados en la Villa se consumieran dentro de los términos de la misma ${ }^{58}$, penando a aquellos que consumieran caldos de otro origen con una multa de $100 \mathrm{mrs} .^{59}$

Se establecieron las medidas que se utilizarían para el vino. Se recurrió en este caso a las medidas de Toledo, tal como lo señalaba una Real Provisión de $1513^{60}$, especificando las medidas del vino asi de arrobas asi como de cantaras Asunbres medias asunbres o cuartillos que sea la medida toledana en todos los myos reynos e senorios no se compre ni benda por granado ni menudo salbo por esta medida ${ }^{61}$. Así pues los bilbaínos hablaban de sus vinos en arrobas, azumbres y cuartillos ${ }^{62}$.

\subsection{Tiempo de Franca - Tiempo de Viedo}

Desde comienzos del siglo XV aparecen en los textos dos palabras que tendrán relación directa con el tratamiento, la conservación y la legislación de los vinos tanto locales como foráneos. Más bien, toda la jurisprudencia relacionada con la vitivinicultura se hará a partir de las regulaciones llamadas franca y viedo o veda, que se referían respectivamente a los periodos de libre comercio de vinos foráneos y a la prohibición de su introducción y venta.

La definición de franca apareció por primera vez en la ratificación que hace el Monarca Enrique III de las Ordenanzas Municipales de Bilbao. Se regulaba que una vez consumidos los vinos locales, el Concejo autorizare traer vinos de otras zonas desde el día de San Miguel hasta quince días después. Igualmente, ordenaba que si en otra época se introdujeran vinos foráneos no pudieran expenderse hasta el dicho día ${ }^{63}$.

que en el tienpo que los vinos de la villa fueren gastados que el concejo general viendo que los dichos vinos son gastados mande traer vino de fuera en tales tienpos que asi fueren demandar que otorgue el concejo desde el dia de santmiguel de cada año que asi ayan a mandar que sean francos los vinos de fuera fasta quinze dias siguientes el dicho dia Sanmiguel no en mas so las penas que de aquí de uso se contienen y ten los binos que en la franquia fueren entrados a la villa no se gas-

${ }^{58}$ 0199/001/026. Privilegio de 1399.

59 Ibidem, 0039/001/001. Bilbao, 1480.

60 Ibidem: 0016/001/030. Valladolid, 13 de mayo de 1513.

61 lbidem.

${ }^{62}$ La arroba o cántara castellana tenía 16.365 litros se dividía en media cántara, azumbre, medio azumbre, cuartillo, medio cuartillo y copa. El azumbre equivalía a cuatro cuartillos o sea 2 litros. Era la octava parte de la cántara. El medio azumbre equivalía a 1.11 litros. El cuartillo era la cuarte parte del azumbre, es decir 0.504 litros, y a su vez equivalía a 4 copas. BASAS, M: Antiguo sistemas de pesos y medidas. Bilbao, 1980, p. 20, 36 y 39. Puede verse también Colección documental..., Op. Cit., Doc. 363, p. 1173 a 1174. Real Cédula a petición de las Juntas de las Villas: Ytem, que la medida del vino, así de arrobas como cantaras asumbres o medios asumbres o quartillos, que sean la medida toledana. Valladolid, 12 de mayo de 1513.

${ }^{63}$ Colección documental..., Op. Cit., p.Doc. 47. Valladolid, 29 de setiembre de 1399. 
taren fasta el dicho termino de Santmiguel en quinze dias que los que fincaren los dueños que los saquen de la villa del termino / si los dueños no los quisieren sacar que los oficiales de la villa acosta de tales vecinos que los saquen de la villa en todo el termino. ${ }^{64}$

El tiempo de la libre circulación, por lo tanto, correspondía desde el 29 de setiembre al 11 de noviembre de cada año. $Y$ así parece haberse cumplido año tras año. En 1509, precisamente el 29 de setiembre, día de San Miguel, el Concejo reguló la licencia de la franca correspondiente a ese año diciendo $A$ los que quieren traer vinos de fuera y vender hasta el día de San Martín ${ }^{65}$. Es decir, dejaba estipulado que, por motivos de escasez, el período se podría ampliar. La ordenanza fue ratificada en 1498 cuando el Consistorio prohibió la entrada de vinos a la Villa y dispuso que los caldos en existencia se vendieran hasta el día de San Martín ${ }^{66}$. Así pues, a lo largo de los siglos XV y XVI serán frecuentes las referencias a esta normativa, debido a la afluencia en cualquier época del año de vinos foráneos y a las constantes denuncias y pleitos con motivo de su reiterado incumplimiento.

Definido el periodo de franca, es sencillo deducir cuál era la época en la que se prohibía la introducción de vinos foráneos, es decir de viedo o veda. Era la obligatoriedad de consumir caldos locales, asegurada por el cierre del mercado a los forasteros hasta que aquellos se agotasen. Obviamente esto beneficiaba a propietarios de cepas ${ }^{67}$. Corresponde al lapso comprendido, aproximadamente, entre mediados de noviembre y fines de agosto, que era el momento, que se suponía, había existencia de vinos locales. Efectivamente, en 1520 un decreto del Municipio establece la temporada del viedo para los vinos; desde el día 7 de setiembre ningún vecino compre, meta, o alonje ningún vino en las bodegas de la Villa, sino solo el vino de sus heredades ${ }^{68}$.

Ahora bien, estos periodos no se cumplían estrictamente porque, evidentemente, la producción local no llegaba en algunos momentos a cubrir ni tan siquiera el consumo de un cuarto del año. Ello ocurrió, por ejemplo, en 1515 cuando a mediados de año se da licencia para la introducción de vinos por la falta de caldos que se observa en la Villa ${ }^{69}$. El periodo de viedo tenía esos plazos orientativos pero, si se agotaban los vinos locales, se finalizaba el viedo, permitiéndose la introducción de vinos foráneos.

La época del viedo era flexible ${ }^{70}$, dependiendo de la cantidad de vinos producidos anualmente tras la cosecha local. Pero, como se observa en la regulación de

${ }^{64}$ DFB - AF, AMB, SA: 0199/001/026. Privilegio de Enrique III.

${ }^{65}$ Libro de Acuerdos, Op. Cit., p. 133.

${ }^{66}$ Colección Documental..., Op. Cit., p. 775 a 776. Bilbao, 5 de noviembre de 1498.

${ }^{67}$ ENRÍQUEZ FERNÁNDEZ, J., SESMERO CUTANDA, E.: Bilbao Medieval, Op. Cit., p. 75.

68 Ibidem: Doc. 454. Bilbao, 7 de setiembre de 1520.

${ }^{69}$ Libro de Acuerdos..., Op. Cit., p.280 y 303. Bilbao, 9 de noviembre de 1515. y 13 de agosto de 1515.

70 Sobre las modificaciones de los periodos de viedo y franca puede verse también: DFB - AF, AMB, SA: 0172/001/031. Bilbao, 12 de agosto de 1583. 
la franca, se deja pie a otorgar fianza o licencia si éstos escaseaban. Por lo tanto la misma jurisprudencia evidenciaba la necesidad de recurrir al vino foráneo.

En Bilbao, como en otras villas del Señorío, la oferta local no llegaba nunca a abastecer el propio mercado de cosecha a cosecha. El consumo de vino parece ser tan alto y la oferta local tan exigua, que el fraude se daba por sobreentendido. Y el Concejo no lo desconocía. Y además sacaba provecho para sanear la cuenta de «propios». Luego, toda legislación era papel mojado, a satisfacción de unos y de otros.

Pocos años más tarde, en el contrato correspondiente a 1581, se modifican los términos del viedo y la franca, como así también el número de tabernas permitidas, en cada caso. En el tiempo del viedo debía haber dos tabernas de vino blanco de Castilla, y una de vinos andaluces, y que en caso de no contar con vino andaluz, se impusiera una más de vinos de Castilla. Mientras que una vez concluido éste periodo, y hasta el próximo día de San Miguel, se podían permitir cuatro tabernas de vino de Rivadavia, dos de vino de Castilla y una de Andalucía ${ }^{71}$. Sin embargo, los comerciantes de la Villa no dejaron de intentar vender vino foráneo en otras épocas. Llegaron incluso a las altas instancias judiciales, como la Real Chancillería de Valladolid intentando recuperar lo que ellos creían sus derechos mercantiles ${ }^{72}$

El Concejo, antes de formalizar cada contrato, consideraba varios factores: 1). El tiempo que la producción local podría abastecer las necesidades de la Villa; 2). La oferta de vinos blancos castellanos y andaluces; 3). Su necesidades recaudatorias y; 4). La necesidad de evitar la difusión de tabernas y ventas al menudeo ilegales. Este conjunto de factores constituirán una de las principales causas de una tensión constante entre autoridades, renteros y consumidores. Y el Ayuntamiento, en ocasiones, se verá sobrepasado por una ingente demanda foránea a la que tendrá que ceder, mediante licencias, para mantener abastecido el mercado.

\subsection{Los actores}

Que la vitivinicultura en esta época era una actividad secundaria no cabe duda, lo cual no obsta para que su legislación no sea escasa. Sin embargo, su peso específico se mide especialmente en la influencia de los viticultores dentro del Concejo. De hecho no existió en Bilbao una asociación de cosecheros, con verdadero peso específico, como en otras ciudades peninsulares, como es el caso de Segovia o de los instituidos por las Ordenanzas en Salamanca ${ }^{73}$. Aunque, como producto de la ordenación surgida en $1399^{74}$ aparece la Cofradía de San Gregorio

\footnotetext{
71 Ibidem: 0172/001/027. Bilbao, 24 de julio de 1581

72 Ibidem: 0054/002/003. Valladolid, 1588. Provisión Real del Felipe II.

${ }^{73}$ MARTíN, J. L.: «El vino, alimento, medicina y alegría», en Historia 16. Madrid, 1994, nº 223, p. 110 y 111.

${ }^{74}$ Fuentes Documentales..., Op. Cit. Documento citado.
} 
Nacianceno, santo protector de los viñedos. Fue ésta, al decir de Enríquez Fernández y Sesmero Cutanda, una Cofradía profesional y no penitencial; y coincidimos con estos autores sobre la escasa información que existe sobre el funcionamiento y desarrollo de la misma ${ }^{75}$.

La frase «las riquezas son mudables, la tierra es cimiento» es manifiestamente consciente para los dueños de la tierra que, animados por las limitaciones impuestas a la introducción de vinos de fuera de la jurisdicción, fueron ganando terrenos para viñedos, con la complacencia de caseros propietarios y comerciantes; pero desconocemos cuál fue la posición de la Cofradía al respecto ${ }^{76}$. Esta condición de grupo de segundo orden, no sólo se observa en Bilbao, sino también en Vitoria, porque aunque en las Ordenanzas de 1423 se dice que esta ciudad está llena de viñas y de bodegas, desaparecen para el siglo XVI por la falta de producción y la mala calidad de los vinos obtenidos, viéndose en la obligación de importarlos del Condado de Treviño y de Navarra ${ }^{77}$.

Las autoridades regían sobre las condiciones en que los trabajadores de las viñas debían realizar las labores. En este sentido llama la atención la dureza de trato que se daba a esta gente, dureza que parte de la misma jurisprudencia. La legislación se involucra en la jornada laboral, alimentación y tratamiento de estos trabajadores, multando a todos aquellos propietarios que no siguieran las normas instituidas.

La vitivinicultura de minifundio ha sido una actividad prolongación de la vida doméstica. En ésta participaban los miembros de la familia y en determinados momentos del año, si las manos no alcanzaban, se contrataba a personal externo. Por lo general en las viñas trabajaban también las mujeres, como lo hicieron todas aquellas que pertenecían a familia de agricultores. La participación femenina dependía especialmente de la extensión de la heredad.

En el caso de los viñedos bilbaínos se contrataban hombres para los trabajos extraordinarios. Generalmente se trataba de labradores, obreros especializados en el tratamiento del viñedo, personajes muy diferentes al campesino que gestionaba un caserío entero ${ }^{78}$. Sorprendentemente el Concejo prohibía dar de almorzar a ningún cavador, ni trabajador de viñas, huertas o manzanales, excepto en la época de plantación de las vides, so pena de $100 \mathrm{mrs}$ al propietario y $50 \mathrm{mrs}$. al trabajador. Asimismo, prohibía dar de merendar a cualquier obrero ${ }^{79}$.

Esta situación no debe llevarnos a confusión. El ordenamiento responde, sin duda, a la necesidad del Consistorio de aumentar el consumo de alimento en tabernas y mesones. La mayoría de las tabernas eran públicas. Era otra forma de

\footnotetext{
${ }^{75}$ ENRÍQUEZ FERNÁNDEZ, J., SESMERO CUTANDA, E.: Bilbao Medieval, Op. Cit., Cap. III.

${ }^{76}$ Ibidem.

77 PORES MARUJÁN, M. R.: Alimentación..., Op. Cit., p. 252.

${ }^{78}$ ENRÍQUEZ FERNÁNDEZ, J., SESMERO CUTANDA, E.: Bilbao Medieval, Op. Cit., p. 95.

${ }^{79}$ Ordenanzas..., Op. Cit., p. 45. Bilbao, 17 de mayo de 1482.
} 
asegurarse mejores rendimientos en estos sitios, para más tarde la institución obtener sus beneficios ya sea en las posturas de arrendamientos, ya a través de los impuestos al consumo, como se verá más adelante.

En Bilbao, dentro del ámbito social que se moviliza en torno al vino, alcanzan mayor relevancia los arrendadores y los taberneros; ellos constituyeron el principal grupo de presión del sector frente al Concejo. Y por supuesto, a ellos está dirigida una larga lista de normas que nos permiten comprender cómo el vino se convierte en una suerte de nexo de sociabilidad, ingresos seguros, y abasto suficiente.

\subsection{Calidad}

Las condiciones climatológicas y edafológicas de Bilbao no eran idóneas para la expansión del cultivo. La graduación alcohólica de un vino depende de tres factores: características del terreno, grado de insolación y pluviosidad de la zona. Bilbao no cumplía ninguno de los requisitos para obtener caldos de calidad aceptable, por mucho que se empeñara el Concejo en sostenerlo. En 1535, con motivo de verse un pleito por la introducción de chacolí de Bermeo contraviniendo las Ordenanzas de la Villa, los introductores declaran que vuestras mercedes todos o los mas tienen vinos de fuera para su provision por causa de ser los vinos de esta villa pestiferos. Afirmaban, como buenos conocedores de la producción de la Villa, que si en manera fuesen bien informados mandarian quemar todas las biñas de esta villa. Ésta no era una opinión de un advenedizo, sino de un productor local: é yo consiento que se quemen las mias con tal que se quemen todas y las mias las primeras aunque soy uno de los que mas biñas tienen en esta villa por el bien que a la republica ${ }^{80}$.

El introductor, que era vecino de la Villa, reconoce con esta declaración una realidad. Primero, que los vinos de la Villa eran de mala calidad; segundo, que las vides se pudrían por la humedad y la lluvia, de ahí la pestilencia; tercero, que la producción local no era suficiente para abastecer el mercado; y cuarto, que introducían lo que la demanda requería. Al parecer, la Villa consideró esta opinión como una afrenta porque taxativamente declaró, que la prohibición de expedir en la Villa vinos que no sean de su jurisdicción, se fundamenta en que no se debate sobre esto ni de los binos de la Villa é de la cosecha della son buenos o malos quanto mas que es notorio son muy buenos y sanos e de las biñas que los vezinos é moradores de la dicha Villa tienen é de la conservacion dellas redunda é se sigue mucho provecho a la republica de la dicha Villa ${ }^{81}$.

El Concejo defendía el cumplimiento de sus Ordenanzas, pero también era su deber predicar la bondad de sus vinos frente a los foráneos. Lo cierto es, como ve-

${ }^{80}$ DFB - AF, AMB, SA: 0051/001/001. Bilbao, 1535.

81 Ibidem. 
remos más adelante, que la calidad de los vinos locales debió ser regular, porque los caldos solían avinagrase con rapidez por dos motivos: la mala calidad del producto y el tipo de envase para su conservación. Asimismo solían mezclarse con otros vinos, a fin de mejorar la calidad ${ }^{82}$.

Tan es así que una orden estipula que ninguno ose mesclar ni remostar vinos viejos con vinos nuevos, ni vender vino remostado, so pena de mil maravedis y que perda el vino ${ }^{83}$. Poco más tarde se decide que nadie venda vino bueno ni malo sin pasar por el registro del Consistorio ${ }^{84}$. Al parecer, las normas no cumplían el efecto deseado porque se insiste que no se mescle vino bueno con un aventado o del mal sabor, olor, so pena de perder el vino, la cuba y pagar una multa de 1000 maravedíes ${ }^{85}$.

La preocupación por la conservación y calidad ${ }^{86}$ de los vinos llegó a ser tal que, ante la venta de los vinos locales podridos o dañados a precios de caldos en buen estado, el Concejo decidió nombrar veedores para velar por las condiciones del producto ${ }^{87}$. $Y$ aunque no duda en proteger a sus vinos y legislar contra la introducción de productos foráneos, la realidad se impuso y en Bilbao se consumieron vinos de variado origen y de diferentes calidades, al menos con cualidades reconocidas en la época como «aceptables»88.

\section{EL VINO FORÁNEO}

La legislación bajomedieval y moderna, ya sea expedida por la Corona o por el Concejo de la Villa, define al vino foráneo como aquellos caldos que procedían de fuera de la jurisdicción de la Villa, sean éstos de ciudades colindantes, cercanas, peninsulares o extranjeras. Este tipo de normativa apareció muy tempranamente, lo que significa que casi desde el mismo momento en que se conformó el andamiaje urbano de la Villa se están introduciendo vinos de otras regiones. Una oferta local insuficiente sólo podía superarse mediante la importación.

Este fenómeno no sólo está en relación con el comportamiento del mercado, sino con el despliegue de vinos de buena calidad de diversas regiones que sedu-

82 Libro de Acuerdos..., Op. Cit., p. 28. Bilbao, 3 de febrero de 1509.

${ }^{83}$ Ibidem, p. 132. Bilbao, 29 de setiembre de 1509.

84 Ibidem, p. 138. Valladolid, 18 de setiembre de 1509.

$85 \mathrm{Ibidem}$, p. 153. Bilbao, 8 de noviembre de 1509.

${ }^{86}$ La calidad tiene que ver también con el tipo de envase utilizado para su guarda. Los odres o cueros no eran los continentes adecuados por el tipo de material usado y las cubas tampoco por la dificultad de estancarlos. En ambos casos el aire que traspasa el envase aumenta el proceso se oxigenación de los caldos hasta llegar a avinagrarlos o torcerlos. Este proceso se manifiesta en forma más virulenta en los caldos conducidos por mar.

${ }^{87}$ Libro de Acuerdos..., Op. Cit., p. 279. Bilbao, 18 de setiembre de 1515. Se nombra como veedores del vino a Juan Martínez Salcedo y Pero de Arys.

${ }^{88}$ los vinos solían aguarse sobre todo en las tabernas. 
cen a las clases pudientes; éstas aprovechan esta coyuntura para manifestar su superioridad económica. Por mucho que las autoridades quisiesen poner coto a estas introducciones, la clase dirigente, y no sólo ésta sino también otros estamentos requerían que el mercado les proveyera de estos productos.

La introducción de caldos de diversas procedencias fue un mal endémico dentro de la economía de la Villa. A mayor número de normas, más eran los artilugios que se utilizaban para introducirlos. Pero, quizás, al gobierno de la Villa estas importaciones no le venían del todo mal. Porque si bien las prohibieron, aceptaron que, una vez dentro de la Villa, podían ser embodegados y guardados hasta que llegase el momento en que el mercado local mostrara claros signos de escasez de vinos propios. Era una tensión permanente entre el Concejo, los proveedores y los taberneros.

Desde el Privilegio de $1399^{89}$, y más tarde en las Ordenanzas de Bilbao, se insiste en la consabida prohibición. Se prohibía su introducción por tierra o por mar. Los propios comerciantes de la Villa conocedores del mercado vitivinícola introducían "calladamente» importantes cantidades de vino foráneo ${ }^{90}$. En 1535 en el pleito contra vinos de Bermeo se dice que en algunos momentos se había consentido la entrada de estos caldos, con la condición de que se encubaran y guardasen; pero esta orden fue sustituida por otra que mandaba que las bodegas sólo se utilizaran para guardar vinos de los vecinos ${ }^{91}$.

El Concejo, conocedor de la situación, decidió:

ordenamos que en el tienpo que los vinos de la suha villa fueren gastados que el concejo general biendo que los suhos binos son gastados que mande traer vinos de fuera en tales tienpos que asi fueren de mandar que otorgue el concejo desde el dia de Sanmiguel de cada año que asi ayan a mandar que sean francos los binos de fuera fasta quinze dias primeros siguientes de al suho dia de sanmiguel no en mas so las penas que aquí de uso se contienen y los binos que en la franquia fueren entrados a la villa no se gastaren fasta el suho termino de sanmiguel en quinze dias que los que fincaren los dueños que los saquen de la villa del termino I si los dueños no los quisieren sacar que los oficiales de la villa acosta de los tales vinos que los saquen de la villa de todo el termino92.

Lo cierto es que esta orden dio lugar a un fluido tráfico de importación que fue de muy difícil contención por parte de las autoridades. Estas entradas eran tanto a granel, como al menudeo ${ }^{93}$. Las autoridades mostraban al respecto un comportamiento sinuoso, dependiendo de la coyuntura y del volumen de vino en el mercado.

\footnotetext{
${ }^{89}$ DFB - AF, AMB, SA: Documento citado.

${ }^{9} \mathrm{Ibidem}$. 0001/002/019. Bilbao, 1420.

${ }^{91}$ Ibidem. 0305/001/007. Bilbao, 3 de agosto de 1535.

92 Ibidem.

${ }^{93} \mathrm{Ibidem}$. 0054/002/002. Autos promovidos por el Alcalde de Bilbao. Bilbao, 8 de enero de 1548. « $\ldots$ que se goarde la orden mia en que dize que ningun bezino ni forano no sea osado de meter [...] ni a menudo ninguno vino tinxo ni blanco [...]”
} 
Tal vez por eso hacia el 1500 se impone una tasa sobre el vino blanco, que más tarde se aplicará a todos los vinos importados, dependiendo de su procedencia y, suponemos, de la cuota de consumo ${ }^{94}$.

\subsection{Formas de introducción}

Pero ¿cómo se introducían estos caldos? Lo hacían por mar y por tierra. Por mar, en un número relativo de botas en los barcos que traían otro tipo de carga. No hemos encontrado embarciones que sólo introdujeran vinos a la Villa. Al referirnos a barcos lo hacemos en forma genérica, ya que también la documentación alude a embarcaciones de pequeño tonelaje como las pinazas. Las primeras órdenes que prohíben este tipo de introducción se remiten a 1420 y, por supuesto, forman parte de las Ordenanzas de la Villa y se refieren a pinazas, batel o navío. Las penas para estos contrabandistas eran muy elevadas, ya que perdían el vino, y se quemaban las botas o las cubas.

La lucha de la Villa para frenar las descargas vínicas de las embarcaciones en su jurisdicción o en las villas cercanas se extienden a lo largo de los siglos XV y $\mathrm{XV}{ }^{95}$. A mediados de siglo XVI, una carta ejecutoria expedida con motivo de un pleito entre la Villa y las anteiglesias por esta causa, ordena que no se pueda descargar ni pan, ni vino, ni sal ${ }^{96}$. Esta carta es otra más de una larga lista que se inicia en 1450 y continúa a lo largo de los años 1497, 1505, 1506, y 154197. Pero estas medidas, como tantas otras relativas al vino, no lograron contener las entradas furtivas. Por lo cual el Concejo, sabiendo que de alguna manera tenía que controlar una actividad que iba en aumento, resuelve que el vino foráneo que entrase en la Villa se encubara y embodegara, y que las llaves las custodiaran los fieles de la institución ${ }^{98}$.

Tal resolución se aplicaba tanto a los vecinos de la Villa que tenían vinos importados en su poder, como a aquéllos que llegaban en embarcaciones regulares o mediante arribadas maliciosas. Así pues, la primera resolución de este tipo se remonta a 1482, cuando en mayo se da licencia para que se permita la entrada de vino foráneo hasta el momento en que declarase la franca ${ }^{99}$. Inclusive se llega a legislar cada año la temporada del «viedo» para los vinos foráneos ${ }^{100}$.

${ }^{94}$ Ibidem. 0016/001/003. Granada, 26 de Noviembre de 1500.

${ }^{95}$ Colección documental..., Op. Cit., p. 911 a 926. Ejecutoria a favor de la Villa de Bilbao Sobre carga y descargas de vino, sal y pan. Libro de Acuerdos..., Op. Cit., Bilbao, 3 de enero de 1509. Varios comerciantes tenían vinos blancos de Andalucía en el Canal de la Ría.

${ }^{96}$ DFBAF, AMB, BSA: 0067/001/001. Zaragoza, 23 de diciembre de 1549.

${ }_{97}$ Ibidem. 0044/003/003. Bilbao, 28 de julio de 1751. Ver también Ibidem, 0044/003/004. Salamanca, 10 de marzo de 1506.

${ }^{98}$ Ibidem, 0054/002/001. Bilbao, 1541.

${ }^{99}$ Ordenanzas...., Op. Cit., p. 43. Bilbao, 17 de mayo de 1482.

${ }^{100}$ Colección Documental..., Op. Cit., p. 1697. Bilbao, 7 de setiembre de 1520. 
Con respecto a los vinos trasegados por tierra, lo hacían en mulas. Y, serán pues, los mulateros asiduamente citados en las normativas restrictivas. En estas ocasiones, como sucedió hasta mediados del siglo XVI, se ordenaba vaciar los odres y pagar una multa de $200 \mathrm{mrs}$. por cada vez que lo hicieren. Desde muy tempranamente los mulateros fueron un grupo perseguido y controlado por las autoridades. Éstos eran muy astutos. En ocasiones no llegaban hasta la jurisdicción, sino que eran los vecinos quienes salían en su busca. Este sistema era utilizado tanto por particulares ${ }^{101}$ que querían hacerse con unos pocos azumbres, como por las regateras ${ }^{102}$, que vendían vino al menudeo.

Desconocemos, de momento, los volúmenes introducidos por estos medios. Lo cierto es que por los testimonios, debieron ser cantidades importantes, porque los mismos vecinos reconocen la necesidad porque si no se hiciesen descarga antes se despoblaria porque se hacia muy poco vino de cosecha que no basttaria sin los vinos de fuera para sustentar en la quarta parte del año ${ }^{103}$. Pero entendemos que, básicamente, el comercio marítimo proveería a granel, en tanto que el terrestre, de mulateros, lo haría en cantidades reducidas. Asimismo, entendemos que los primeros proveían a los grandes almacenistas, en tanto que los segundos al grupo que vendía sin licencia, como es el caso de las regateras y las casas y tabernas ilegales.

\subsection{Orígenes y variedades}

La variedad de vinos que se introducía en Bilbao no deja de llamar la atención, tanto por su procedencia, como por su variedad. Blancos, tintos, claretes, bermejos si se refiere a su tono; ácidos, dulces, afrutados, secos y semisecos, si se considera su sabor. Ahora bien, en relación a su origen se dividen en vinos peninsulares y extranjeros. Peninsulares: de Plasencia, Toro, Madrigal, Medina del Campo, Yépes, Madrid, Monzón, Navarrete, Navarra, Sanlúcar, Jérez, Cádiz'104, Málaga, Cantabria (Castro), La Mancha, Logroño, La Rioja, Galicia, Valencia (Gandía) y Canarias. Extranjeros: Bayona, Burdeos, La Rochela, Saint Malo ${ }^{105}$ Portugal e Irlanda.

Sin embargo, a pesar de saber su procedencia, son pocos los datos relativos a la variedad del vino. Escasas referencias indican que estaríamos hablando de Moscatel, Malvasía ${ }^{106}$, Oporto y uno llamado «bastardo», que no hemos podido

${ }^{101}$ Ordenanzas..., Op. Cit., Bilbao, 27 de setiembre de 1487.

102 Ibidem, p. 71. Bilbao, 13 de setiembre de 1490.

103 DFB - AF, AMB, SA: 0044/003/005. Bilbao, 13 de Noviembre de 1554.

${ }^{104}$ Para el tratamiento de los vinos andaluces, especialmente gaditanos y de los vinos de Jérez puede verse los trabajos de Javier Maldonado Rosso y Alberto Ramos Santana de la Unidad de Estudio del vino de la Universidad de Cádiz.

105 GUIARD Y LARRAURI, T.: Historia del Consulado de Bilbao. Bilbao, 1972, T. I., p. XXXII.

106 Sobre este varietal y las características de sus vinos puede verse: MACÍAS HERNÁNDEZ, Antonio: «La vitivinicultura canaria. Orto y Ocaso, 1500-1850», en Actas del I Encuentro..., Op. Cit., p. 321. 


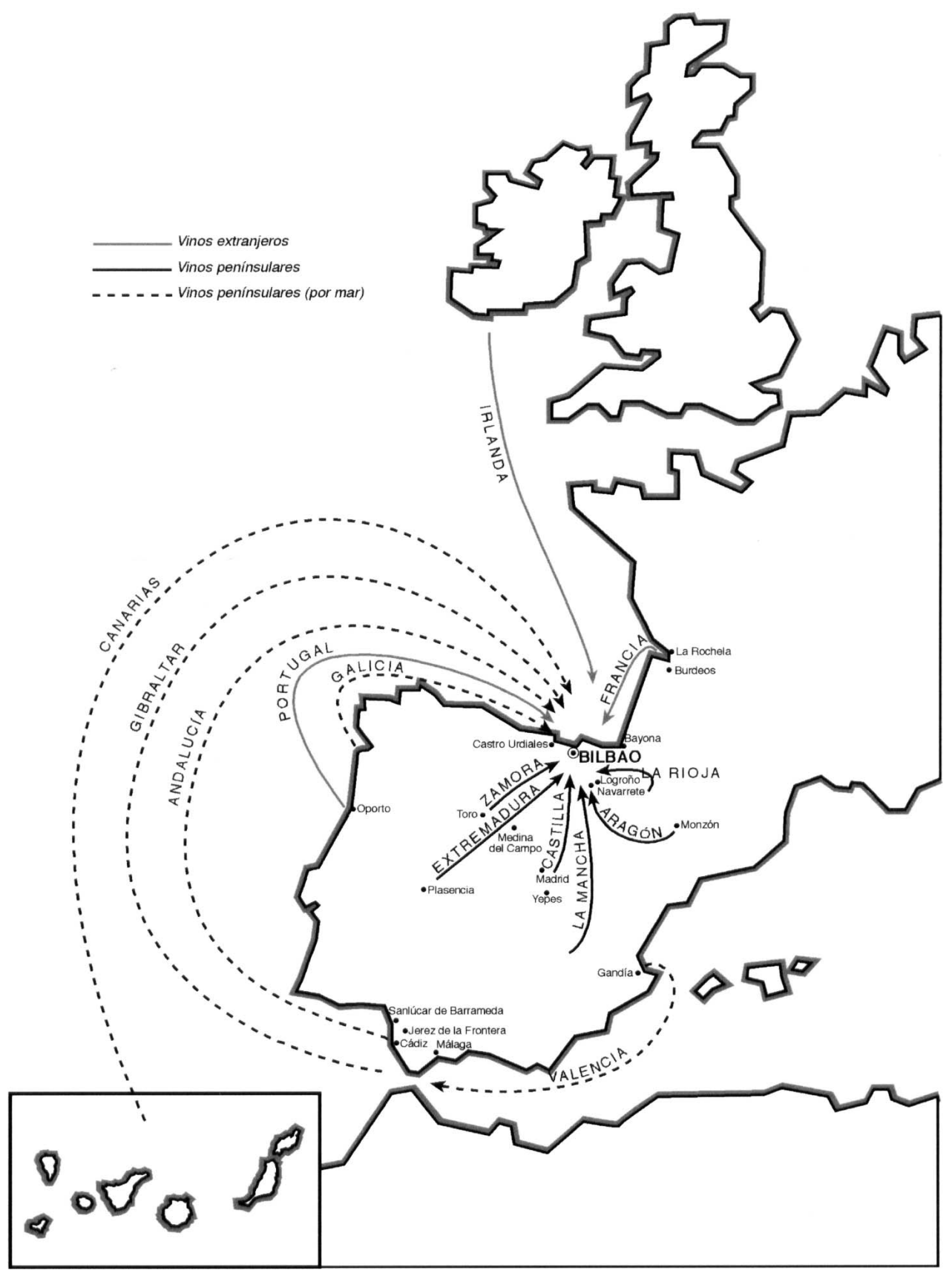

Procedencia de los vinos foráneos que llegan a Bilbao. Siglo XVI. 
identificar. Este comercio de vino en Bilbao demuestra que la Villa recibía los principales y más característicos vinos del momento, como así también los más apreciados: es el caso del Burdeos, Oporto ${ }^{107}$ y Malvasía. Vinos de excelente calidad, aunque no perfectos, porque debieron aguardar al siglo XVII, concretamente a la aparición de la botella de cristal y del corcho, para lograr un estado de conservación adecuado, y un cuerpo en boca tal como hoy los conocemos.

El hecho de que aparezcan estos vinos en el mercado bilbaíno demuestra, entre otras cosas, que había sectores sociales con cierta capacidad financiera para adquirirlos, y nos indica igualmente que, tal como ocurre en Francia, el consumo en la Villa se convierte en degustación, y la degustación en lujo, y éste es una cuestión de clases $^{108}$.

\section{EL PAISAJE MERCANTIL}

\subsection{Mercado}

El movimiento de la oferta y la demanda marcan el tono del mercado. En Bilbao, la oferta del vino propio era escasa para mantener una demanda en crecimiento. Al comenzar el siglo XVI había en la Villa unos mil hogares ${ }^{109}$ y el desarrollo marítimo, comercial y económico hacía prever una tendencia al aumento. Porque a la población residente se debe agregar la transeúnte, dada la importancia del puerto de la Villa. Luego la producción local de caldos era a todas luces insuficiente, si consideramos un consumo promedio per cápita de entre 150 y 250 litros/año.

Cuadro 1: Evolución de la población de Bilbao

\begin{tabular}{|c|c|c|}
\hline Año & Habitantes & Otros \\
\hline 1492 & 1.253 aprox. & 1.037 fogueras ${ }^{110}$ \\
\hline 1511 & 1.406 aprox. & 1.276 fogueras \\
\hline 1514 & 1.615 aprox. & 1.398 fogueras \\
\hline
\end{tabular}

Fuente: Elaboración propia a partir de: Enríquez, Javier, Sesmero, Enriqueta: «Bilbao Medieval», p. 52

\footnotetext{
${ }^{107}$ Para el tratamiento del Oporto se pueden ver diversos trabajos de Francisco Ribeiro da Silva y Antonio Barros Cardoso de la Universidad de Porto.

${ }^{108}$ DUHART, F.: «Vinos Escogidos», en VIII Seminario Iberoamericano: La Vid y las Ciencias Sociales». Talca, Universidad de Talca, 2006. Del mismo autor:: « Los «vinos de arena» del litoral gascón desde el siglo XVIII: un ensayo de antropología histórica de la duna a la mesa. ", IV Simposio de la Asociación Internacional de Historia y Civilización de la vid y del vino. Haro, 2004.

109 MENÉNDEZ PIDAL, R.: Historia de España. Madrid, 1996, T. XII, p. 36.

110 Proviene de fogueración: numeración de hogares o fuegos.
} 
A la variable demográfica y productiva hay que sumar la del tipo de caldos que allí se producían. Aparentemente, y según las fuentes, en la legislación todo indica que estamos ante la presencia de una oferta constituida casi en exclusiva por vinos tintos, escasez de vinos blancos y discretos volúmenes de sidra. Ésta será una constante con la que el Ayuntamiento tendrá que bregar a lo largo de los siglos. Además, la permeabilidad de las fronteras, imaginarias y reales, de la jurisdicción de la Villa, la convertían en una puerta idónea, tanto por tierra como por mar, para introducir caldos de origen peninsular y europeos.

De suerte que se erige un Concejo controlador del mercado, pero a la vez protector de sus productos, que además debía asegurar el abastecimiento de los habitantes del Nervión. Toda una paradoja. Ante tal disyuntiva, procederá a legislar al efecto, como otras ciudades y villas bajo medievales y modernas. Impondrá primero el arrendamiento del vino blanco.

Las primeras noticias sobre el arrendamiento de vino blanco en la Villa se remontan a un Privilegio confirmado por la Reina Isabel La Católica, concediendo a Bilbao la facultad de arrendar perpetuamente vino blanco en estos términos: Arrendar cada año para siempre jamás la dicha renta... e para que los maravedis que asy se arrendaren sean para los propios de dicho Concejo y para gastar e distribuir en las cosas colinderas a mi servicio e bien e publica utilidad de la dicha villa en reparo de los muros, cays e puentes della... ${ }^{111}$

El Privilegió se ratifica más tarde en la Ejecutoria, en el pleito que mantenían entre el Señorío y la Villa sobre ordenanzas, imposiciones y sisas. En esta ocasión, la Villa pedía que se perpetuara la renta para los propios ${ }^{112}$.

La Corona o el Concejo, al establecer el arrendamiento de los productos escasos, lograban que en los momentos de mayor demanda y escasa oferta se facilitara la entrada de vinos de fuera de la Villa, equilibrando de esta manera la oferta y la demanda, y estabilizando los precios, porque la escasez del producto aumentaba irremediablemente el precio; se aseguraba haberes para el mejor funcionamiento del Concejo; y frenaba el fraude y el contrabando o, al menos, se hacía con interesantes sumas procedentes de caloñas, multas. etc. Existieron en la villa más de seis tabernas expendedoras de vino blanco por el sistema de arrendamiento. Éste se pregonaba, había una puja, y por supuesto la postura más alta se quedaba con la taberna y el arrendamiento del vino blanco.

El arrendamiento se pagaba básicamente por cuatrimestres, pero en ocasiones el Ayuntamiento se veía obligado a imponer cuotas extras, ante el aumento del precio de los caldos, sobre todo cuando el producto se sobrestimaba en las Anteiglesias vecinas, y cuando los arrendadores de la Villa presionaban para que se autorizara su aumento. El Concejo lo autoriza, pero a la vez ordena que los arrendatarios paguen una parte alícuota de hasta 3000 maravedís por mes.

${ }^{111}$ DFB - AF, AMB, SA: 0028/001/003. Real Provisión de Carlos I. Ver también Colección documental..., Op. Cit., p. 511/512. Bilbao, 15 de septiembre de 1483.

112 Ibidem, p. 950 a 972 . Burgos, 29 de octubre de 1507. 
El remate, primero se pregonaba, a continuación se iniciaba encendiendo una candela de cera, y cuando ésta se consumía, concluía el remate y se le adjudicaba al mejor postor. En ocasiones el precio pagado por el rentero nos da una idea de los litros que se arrendaban: cerca de 10.000 litros. Cantidad que consideramos insuficiente para abastecer al consumo local.

El volumen arrendado permite comprender por qué tanta introducción ilegal. En el contrato de arrendamiento quedaban fijados el precio del azumbre, la calidad del vino, el origen: San Martín, Madrigal, Yépes, y Medina del Campo; prohibía que otro vecino tuviese o vendiere vino similar. Asimismo se ordenaba que el pago cuatrimestral se hiciera en buena moneda de Castilla ${ }^{113}$.

El sistema resultó ser eficaz, pero también desestabilizador en algunos momentos, ya que con diversas argucias los arrendadores introducían vino en tiempo de veda. De ahí que el Concejo deba hacer una legislación ad-hoc. Así pues, decide que todo aquel que introduzca vino de fuera en la época franca debía encubarlo, embodegarlo y mantenerlo bajo llave hasta que se autorizara su venta.

Yten que la dha villa de Vilvao se pueda prober y bastecer de binos tintos de fuera de la dha villa para en tiempo de franca se diere de qualesquiera binos tintos que los quysiere entrar y meter en la dha villa aunque los binos que asientraren en esta dha villa antes de la dha franca sean y se entienda los binos tintos e petibines blancos e tintos que benieren por mar de castilla asta $q$ se de la dhya franca antes no entren asta la dha franca los dhos tales binos de castilla salbo los que bienen por mar y los que (...) entraren esten alojados en la dha villa asta que se de la franca para los bender por el dho concejo e regimi ${ }^{\circ}$ de la dha villa / con que aya de tener e tengan las llabes de las tales bodegas e lonjas que estubieren los regidores diputados de la dha villa del consejo della e que el arrendador de la dha renta no pueda contra dezir ni contradiga cosa alguna [... $]^{14}$

Pero ésta no fue la solución del problema. Por tres razones: primero, porque en cualquier época del año llegaban embarcaciones con vinos de buena calidad que se introducían sin control; segundo, porque había un virulento comercio ilegal de caldos procedentes de las Anteiglesias vecinas, y de otras regiones, a través de los mulateros; y tercero, por la activa participación de regateras y mozas de taberna vendiendo vino foráneo al menudeo.

En 1499 una Real Cédula ordena que no se haga venta ni reventa de vino foráneo desde Bilbao a Areta, ni desde Baracaldo a Zamudio. Era una realidad que ni la Corona ni el Concejo encontraban la manera de evitar estos negocios que, a todas luces, estaban fuera de su control. Y aunque se afana en crear jurisprudencia, todo es en vano ${ }^{115}$.

Iniciado el nuevo siglo la situación no parece mostrar signos de mejoría. Muy por el contrario, el sistema de arrendamiento del vino blanco no ha frenado la in-

\footnotetext{
${ }^{113}$ Libro de Acuerdos..., Op. Cit., p. 294/297. Bilbao, 5 de octubre de 1515.

114 DFB - AF, AMB, SA: 0170/001/003. Bilbao, 23 de agosto de 1563.

115 Colección Documentad..., Op. Cit., p. 781/82. Ocaña, 21 de febrero de 1499.
} 
troducción de vinos foráneos por parte de los particulares. Es más, el problema de la escasez de oferta de vinos locales parece agravarse, porque a mediados de siglo ya no sólo se arriendan los vinos blancos, sino también los tintos y claretes ${ }^{116}$.

Seguramente el crecimiento de la población, las bonanzas económicas de la Villa, y el aumento de la oferta foránea causaron un total desequilibrio entre la oferta, la demanda y las expectativas recaudadoras del Concejo. De ahí la necesidad de ampliar los productos arrendados y de implementar nuevas regulaciones a tal efecto. Dada la situación de crecimiento económico, las autoridades de la Villa debieron permitir las introducciones, ampliando además los periodos de «franca»"117, como lo hicieran excepcionalmente en otras ocasiones ${ }^{118}$. Sin embargo, la renta siguió existiendo, ya que formaba parte de los «propios» de la ciudad ${ }^{119}$, renglón nada despreciable dentro de la Hacienda Municipal.

Dentro de ésta política se instituyeron, igualmente, las visitas a las tabernas con el fin de reconocer, entre otras cuestiones, la existencia de vinos foráneos, introducidos ilegalmente ${ }^{120}$. Ordenaron sacar o embodegar todos los vinos foráneos, so pena de $20.000 \mathrm{mrs}^{121}$. Estos registros o visitas se extendían a lo largo del todo el siglo, produciéndose en cualquier época del año. En estas visitas el propietario, o persona en su nombre, debía estar presente, controlaban pesos, medidas, precios, aranceles, calidades y origen de los caldos, así como también el estado de la vasija de vinos permitidos ${ }^{122}$.

\subsection{Impuestos}

Sabido es que la financiación municipal de las villas y ciudades se sustentó básicamente en la instrumentación de imposiciones o sisas a los productos de consumo, es decir impuestos indirectos. Estas sisas podían establecerse temporalmente o a perpetuidad, o sea ordinarias o extraordinarias, dependiendo de las circunstancias y del motivo que las propiciaría. Los Concejos iban a remolque de los acontecimientos, y vivían endeudados, ya sea por las necesidades de defensa, o por los mantenimientos de infraestructuras ${ }^{123}$. Siendo el vino un producto de consumo extendido, lógicamente estuvo sometido a este tipo de contribuciones.

\footnotetext{
${ }^{116}$ Diversos documentos de la segunda mitad del siglo XVI de la Sección Bilbao Municipal.

117 Libro de Acuerdos..., Op. Cit., p. 207, 208, 218. Diversas autorizaciones para introducción y venta de vino foráneo.

118 aquí poner lo de fuentes

119 Colección documental..., Op. Cit., p. 261. Bilbao, 11 de junio de 1515.

120 Libro de Acuerdos..., Op. Cit., p. 28. Bilbao, 3 de febrero de 1509.

121 Ibidem, p. 29/30. Bilbao, 5 de febrero de 1509.

122 DFB - AF, AMB, SA: 0512/001/001. Actas de las visitas a tabernas y mesones. Bilbao, junio de 1583.

${ }^{123}$ GARCÍA FERNÁNDEZ, E.: «La fiscalidad concejil en el País Vasco durante la Edad Media (11401550)", en Revista d' Història Medieval. Valencia, 1996, n 7, pp. 81/114. En un excelente artículo el autor analiza las aplicaciones fiscales de carácter municipal en las villas vascas. Concretamente para Bil-
} 
En 1470 la Corona otorgó al Concejo una Licencia Real sobre mantenimientos y mercancías, a fin de arreglar los muros de la Villa y pagar a gente armada que la defienda. Recaía en este caso sobre vino, pan, carne, pescado, hierros, lanas, paños, lienzos, etc. ${ }^{124}$. Las fuentes indican que en ocasiones, el impuesto se aumentaba en algunas anteiglesias, sin el acuerdo del Concejo, ni del Monarca. De ahí que en 1500, los procuradores de Bilbao se dirijan al Consejo de su Majestad a fin de lograr la supresión del aumento de la sisa sobre el vino, establecido en la Anteiglesia de San Vicente de Abando. El Rey responde que se suprima dicha decisión e punir e castigar a las personas que la an puesto ${ }^{125}$.

En setiembre de 1509, mediante una Real Cédula, se ordenó una sisa o impuesto sobre el vino y la carne. Ordenanza que será luego instrumentada por el Concejo de la Villa ${ }^{126}$. Poco más tarde, en el mismo ayuntamiento se discute cómo se cobrará este impuesto. En los debates se dice que con la recaudación de la contribución de ambos productos, en dos o tres años se sanearían los números rojos de la institución. Dicha recaudación podría alcanzar más de 580.000 maravedíes. De tal manera que se dispone que se cobrará en el vino un maravedíe/azumbre (en adelante mrs/a), cuyo ingresó pasará a compensar el rótulo de los diezmos ${ }^{127}$.

La imposición resarciría a la institución de sus deudas, al parecer cuantiosas, pero para lograr este objetivo tendría que regular su cobro. $Y$ rápidamente se ordena que aquel que no pague la sisa pasados seis días de la adquisición del producto, sea multado con $220 \mathrm{mrs}$. por tonel ${ }^{128}$. Igualmente se estableció para el cobro el sistema de arrendamiento. En este caso, el arrendador estaría acompañado por un vigilante o cuidador que le ayudaría en las tareas relativas a la renta ${ }^{129}$.

Hacia mediados de siglo cambia el nombre del arrendamiento de la sisa del vino blanco, pasando a llamarse arrendamiento sobre la sisa del vino blanco de Castilla, Andalucía y Rivadavia. En el contrato correspondiente a 1554 obtenemos mayores precisiones sobre la gestión del impuesto. Así pues, se dice que sólo se pagará en primera venta y que se cobrará tanto de vinos vendidos en grueso como tarbenado, abiendo una vez dha sisa (...) se aya otra benta no pueden llebar por segunda vez la dha sisa ${ }^{130}$.

bao indica que a lo largo del siglo XV la mayoría de los gastos del Concejo se distribuían en gestión administrativa (38\%), obras públicas (33\%) y el «pedido» real (23\%). En tanto que sus ingresos se repartían en rentas $(55 \%)$, repartimientos (25\%), montes $(20 \%)$. Ver Gráficos de las páginas 94 y 95.

${ }^{124}$ Colección documental..., Op. Cit., p. 398/399. Segovia, 15 de junio de 1470.

${ }^{125}$ DFB - AF, AMB, SA: 0016/001/003. Provisión Real dado por los Reyes Católicos. Granada, 26 de Noviembre de 1500.

${ }^{126}$ Libro de Acuerdos, p. 137. Valladolid, 18 de setiembre de 1509.

127 Ibidem, p. 140. Bilbao, 9 de octubre de 1509.

128 Ibidem, p. 151. Bilbao, 8 de noviembre de 1509.

129 Ibidem, p. 305. Bilbao, 23 de noviembre de 1515. El sistema de arrendamiento se impuso a la vez que la sisa. Ahora bien, la figura del «cuidador» aparece mencionada por primera vez en 1515 . Su sueldo dos ducados.

${ }^{130}$ DFBAF, AMB, BSA: 0169/001/005. Bilbao, 31 de enero de 1554. 
Por la misma fecha, y sorpresivamente, aparece el arrendamiento de la sisa sobre los vinos tinto, clarete y blanco de cosecha propia y los foráneos de Francia, Galicia y Monzón. No hemos encontrado con anterioridad este tipo de imposición sobre el tipo de vino fijado. Al parecer, el pasivo de la hacienda de la Villa está aumentando, los gastos se acrecientan y la necesidad de recaudar alcanza a caldos que hasta el momento no estaban gravados. Se fijan las tasas para los vinos tintos y blancos de Francia, Petibinés, de Galicia y de Monzón, en ocho reales de plata castellana la bota y cuatro reales la barrica; al vino tinto de Castilla dos mrs/a $\mathrm{a}^{131}$.

Igualmente, los contratos se hacen eco de la existencia del fraude, aclarando que aquellos vinos que entraran en hostelerías o tabernas a través de sus huéspedes, pagasen igualmente el impuesto ${ }^{132}$. Otro aspecto interesante de los contratos es la forma en que se establece la cantidad necesaria a recaudar, en suma, la mejor subasta para los intereses del Concejo. Sus miembros expresan que dado que tienen licencia real para incluir en los propios de la ciudad hasta 8.000 ducados destinados a los gastos de las obras de la Villa, calculan que por el concepto de este arrendamiento podían recaudar entre 480 y 600 ducados por año ${ }^{133}$.

Al llegar la década de los 70 , ya sea por razones operativas del mismo sistema, por comodidad o por necesidad de incrementar las recaudaciones del Ayuntamiento, los contratos se conceden por dos años ${ }^{134}$. Según parece, el motivo que impulsó el paso al sistema bianual fueron los ingentes gastos de la Villa en mantenimientos y arreglo de los diversos suministros. Tal es el caso de reparación y limpieza de caños y servidumbres de aguas servidas ${ }^{135}$.

Para tal fin, en 1570, por una Real Provisión de Felipe II, se autoriza al Concejo a cargar con un maravedí más en cada azumbre de vino para tal fin. En este caso, el aumento se imponía sobre la sisa del vino de la Villa, es decir de los caldos propios. De esta manera se obtendrían los 1000 ducados necesarios para las reparaciones descritas ${ }^{136}$. Ordena, igualmente, que el dinero recaudado sólo se ocupase en esa obra y no en ninguna otra.

Poco tiempo después de pasar el arrendamiento de anual a bianual, se modifican las condiciones para el nuevo arrendador. El contrato será trianual ${ }^{137}$, establece la tasa según la variedad del vino y se aclara la forma en que se actuará ante situaciones fraudulentas. Pero lo sorprendente de este contrato es que saca a re-

\footnotetext{
131 Ibidem

132 Ibidem. 00169/001/014. Bilbao, 10 de junio de 1554.Ver también. 0169/001/024. Bilbao, 1 de junio de 1554

${ }^{133}$ Ver arrendamientos citados y los correspondientes entre 1555 y 1560 . Signaturas 0169,0170

134 Ibidem: 0170/001/027. Bilbao, 30 de octubre de 1567. Remate del ramo para los años 1568 y 1569. Ver también. 0171/001/004. Bilbao, 1569. Remate para los años 1570 y 1571.

135 Ibidem: 0171/001/058. Bilbao, 26 de agosto de 1575 Esta causa o motivo se cita en varias ocasiones hasta finales de siglo.

136 Ibidem: 0028/001/020. Real Provisión 1568.

137 Ibidem: 0170/001/005. Bilbao, 6 de marzo de 1570
} 
lucir nuevamente la necesidad de contar con 1000 ducados para reparaciones de caños. $Y$ efectivamente la renta se remata por dicha cantidad.

El análisis del arrendamiento de las imposiciones para los caldos de diverso origen permite extraer varias conclusiones. El hecho de que este sistema correspondiera a los propios de la Villa era una especie de garantía, tanto para el Concejo como para la Corona. Para el primero porque, ante diversas necesidades pecuniarias, recurría a gravar productos básicos alimenticios, concretamente el pan y el vino, en una especie de rememoración religiosa. Al tener esta capacidad podía asimismo cambiar las cláusulas contractuales, ya que dependiendo de las necesidades de liquidez, suscribía arbitrariamente las obligaciones por uno, dos o tres años.

Por su parte, la Corona se encontraba envuelta en una difícil coyuntura bélica, lo cual generaba dos consecuencias importantes: por una parte, estaba necesitada de recursos, y, por otra parte, era incapaz de atender lo que podríamos llamar necesidades domésticas, como lo fueron las peticiones de ayuda de los Ayuntamientos, por lo que, a golpe de Real Provisión o Real Cédula, otorgaba facultad a los concejos para gravar los productos más requeridos en el mercado.

De resultas, las dos instituciones salvaban pasivos a través de estas sisas o imposiciones, influyendo negativamente sobre la evolución de los precios de las mercancías cargadas en el mercado. De ahí se explica que el fraude estuviese a la orden del día, fuese común, tolerado y a veces aceptado. Ya se sabe que la norma sucede al hecho. Pues bien, lo que en este período queda claro es que la abundancia de legislación se levanta en una suerte de testimonio y denuncia para aquéllos que analizamos el fenómeno. Y evidencia que en Bilbao el mercado del vino local y foráneo fue activo y vigilado, pero cubierto con un velo que denota la existencia de una economía surtida por ingresos con claros matices recaudatorios, que fluía por sus propios cauces, a pesar de la legislación y el control de unos y de otros.

\subsection{Precios}

Fijar el precio de los caldos era otra de las competencias del Concejo. Sin embargo, la primera referencia sobre el precio del vino de la Villa aparece en 1399 cuando el Rey ordena que se venda al precio que dispusiera el Concejo, pero no se precisa ${ }^{138}$. Poco tiempo después el mismo Monarca, al ratificar las Ordenanzas, establece que los vinos locales se vendieran libres de impuestos y al precio que se mandara ${ }^{139}$. También el Fuero Nuevo hacía referencia a este punto ordenando que fuesen las anteiglesias las que dispusieran los precios ${ }^{140}$.

\footnotetext{
${ }^{138}$ DFB - AF, AMB, SA: 0199/001/026. Valladolid 9 de setiembre de 1399.

139 Colección Documental..., Op. Cit. Valladolid, 29 de Setiembre de 1399. Doc. 47.

140 Fuero Nuevo de Vizcaya, título 1, Ley 10, p. 90.
} 
El control sobre el precio de los productos estaba siempre bajo la atenta mirada del Consistorio, siempre preocupado porque el vino se vendiera a los valores ordenados, imponiendo duras penas al transgresor ${ }^{141}$. Su obsesión era que nadie se impusiera a los precios demarcados en las sesiones ${ }^{142}$. El Concejo regulaba tanto el precio de los vinos locales como el de vinos foráneos, intentando mantener una estabilidad de los mismos, dependiendo de la oferta y la demanda existente.

Las fuentes son más pródigas en datos relativos a los vinos foráneos porque, al estar arrendado su abastecimiento, la frecuencia con que se los nomina es mayor. Por el contrario son escasos los datos relativos a vino de la tierra e, inclusive, su precio parece más estable que el de los importados. Así pues, el precio del vino de Bilbao a lo largo de los siglos XV y XVI no tuvo grandes oscilaciones. Permaneció estable al alza entre 10 1/2 a $12 \mathrm{mrs} / \mathrm{a}$, dependiendo de si se trataba de vino añejo o nuevo. Contrariamente a lo que hoy es común, por lo que se deduce de la documentación, el vino nuevo tenía mayor valor que el procedente de cosechas anteriores ${ }^{143}$.

El precio de los vinos importados oscilaba dependiendo de la época del año y de la oferta. Pero también sus movimientos dependían fundamentalmente, de estar bajo el sistema de arrendamiento que, sin duda, agregaba un porcentaje añadido a su valor en el mercado. Tal es así que se puede encontrar un mismo vino con tres precios diferentes ${ }^{144}$.

El estipendio del vino blanco significaba un constante problema para el Ayuntamiento porque los taberneros y vendedores reclamaban constantemente a las autoridades por el bajo precio de suministro, dado que en otras Anteiglesias el vino se vendía a mayor precio. En Durango, Murguía, Larrabezúa, Miravalles y Arrigorriaga se pagaban $26 \mathrm{mrs}$./a. El Consistorio tuvo que ceder ante la presión y estipuló el precio en $24 \mathrm{mrs}$./a obligando a los arrendadores a pagar mensualmente 3000 mrs. más en razón de quedar su postura en condición desventajosa para la Villa ${ }^{145}$.

Transcurrido el siglo XVI, la situación no fue a mejor porque ya no sólo se discute sobre el precio del vino de acuerdo a su tono, sino también en cuanto a su origen. La diferencia de precios entre los vinos locales y los foráneos supera al alza más del $100 \%$, lo cual no nos debe extrañar porque, como se ha visto, se introducen en la Villa vinos de excelentes calidades, según testimonios de la época. Igualmente sorprende la disparidad de precios en los caldos foráneos, precios que sin duda, aumentan por el gasto añadido que suponían los fletes, ya sean marítimos o terrestres.

\footnotetext{
${ }^{141}$ DFB - AF, AMB, SA: 0199/001/016. Valladolid, 1420. Ordenanzas..., Op. Cit., p. 50 Bilbao, 10 de setiembre de 1487 .

142 Ibidem, p. 53. Bilbao, 23 de setiembre de 1487.

${ }^{143}$ Libro de Acuerdos..., Op. Cit., Bilbao, 22 de Octubre de 1509; 13 de agosto de 1509; 15 de Noviembre de 1515

144 Ibidem, p. 48. Bilbao, 2 de marzo de 1509.

145 Ibidem, p. 56. Bilbao, 14 de febrero de 1509.
} 
También el precio de estos vinos presenta siempre tendencia al alza por la necesidad que había de ellos para abastecer a la comunidad. Es común encontrar en los testimonios frases como en Bilbao hay mucha gente y poca cosecha. Pero no sólo por esto sino porque el consumo iba en aumento. El vino es un producto accesible a todas las clases sociales y en parte, la diferencia entre los consumidores estará marcada por el tipo de vino que consume cada grupo social. El burgués intenta diferenciarse del vulgo consumiendo vinos extranjeros de mejor calidad. Situación que, finalmente, redundará en el precio.

Las referencias de precios de vinos foráneos son más asiduas en aquellos volúmenes procedentes de diversas ciudades o zonas peninsulares. El vino blanco de Castilla, 38 mrs./a; el de Andalucía, 34 mrs./a y el de Rivadavia, 42 mrs./a. ${ }^{146}$.

La diferencia con el precio del vino local es muy grande. En este renglón cabe estimar una influencia decisiva de los fletes y de los impuestos de introducción. Pero también, es evidente que los proveedores se aprovechan de una demanda insatisfecha, dada la escasez del vino local. Además, el elevado precio de los vinos foráneos nos pone sobre la pista de categorías en el consumo, ya que no todos los individuos podían acceder con facilidad a este tipo de caldos. Sin embargo, y a pesar de estos condicionantes, el Ayuntamiento no tuvo otra solución que permitir la entrada de estos caldos.

\section{A MODO DE SÍNTESIS}

A lo largo de este análisis hemos podido comprobar de qué manera los agentes económicos, sociales y políticos de la Villa de Bilbao se ven afectados de una u otra forma a la hora de gestionar la producción y comercialización de los vinos para abastecer a los vecinos.

Paradójicamente, desde el Concejo se intenta velar por la pervivencia de una producción local a todas luces escasa; pero, a la vez, debe regular la introducción de vinos foráneos, ya sea de origen peninsular o extranjero, porque en ocasiones equilibraban las necesidades de la oferta, aunque que en otras podían llegar a saturar el mercado, llegando incluso a bloquear la oferta local.

El universo del vino en el Bilbao bajomedieval y moderno es una muestra de cómo los Ayuntamientos libraban una dura batalla entre el proteccionismo y la libre circulación de mercancías dentro de una jurisdicción. Una lucha en la que se ven involucrados los vinateros, defensores de sus producciones; los comerciantes locales de conducta ambivalente y atentos a las necesidades del mercado; y el Concejo, obligado a proteger la industria local, pero necesitado de ingresos extraordinarios para afrontar el déficit público.

${ }^{146}$ DFB - AF, AMB, SA: 0169/001/005. Bilbao, 31 de enero de 1554. 
Es quizás en el afán recaudatorio e intervencionista del Concejo donde aparece con mayor claridad la paradoja a la que hacíamos referencia. Debe legislar para mantener un equilibrio en el mercado con periodos de franca y viedo, pero también es consciente de que el consumo va en aumento, y con ello las necesidades de la demanda. Entonces, en un afán de no perder el control, amplía los tiempos de libre introducción, porque no tiene otra opción que permitir estas introducciones, porque la producción local es a todas luces insuficiente, pero no sólo eso, sino que además no es una producción de calidad. Bilbao no produce un "vino bueno de dar y tomar».

Braudel, aludiendo a la expansión de la vid en Europa decía que ésta «se regó de vides». Pero la difusión del cultivo no significaba tener asegurada la calidad de los caldos. Y esto era una realidad en Bilbao, donde la propia climatología y la orografía fueron el principal obstáculo para lograr una producción en cantidad y calidad deseada para atender a una demanda en aumento. De ahí que la jurisprudencia tomara un camino, pero la realidad transitara por la vía contraria. 